\title{
أثر اختلاف أنماط دعم الأداء للتدريب عن بعد فى تنمية ههارات الرسم ثلاثى الابعاد لدى هماتمى التعليم الثانوى الصناعى
}

إعداد

أ /مصطفى خلف القصبى خلف

تتميز تكنولوجيا التعليم بالتطور المستمر والسريع في مستحدثاتها، ومن أبرز هذه المستحدثات تكنولوجيا التدريب الإلكتروني، والتي تتطلب المزيد من البحث و التطوير للكشف عن أنسب تصميم لبر امج التدريب الإكتروني كى تتاسب نوعية المتدربين ومخرجات التعليم و التدريب ، و و اذا اقتتع المتعلمون بان المعلمون عن بعد يهتمون بهم وبتعلمهم فسوف يساهم علم التدريب بسرعه مطردة أسوة في ذلك بغيره من العلوم الطبيعية والإنسانية التي تنتافس جميعها في فهم ما بحدث حولنا وفي تسهيل التعامل مع معطيات المو اقف العملية والحياتية معا، ساعد في ذللك هذا التطور التكنولوجي الهام الذي يحدث في مختلف جو انب الحياة . إن التقدم والتميز في عالم اليوم والغد يستلزم بالضرورة تحديدا وتطوير ا مستمر ا في معارف المرء ومهار اته فإن ما نعرفه اليوم سوف يصبح بلا معنى في الغد ما لم نتطور من خلال عملية تعلم مستمر الاحساس بالمشكلة: لقد تطور استخدام التعلم عن بعد الآن وصارت له صور عديدة استجابة إلى التطور الذي حدث في مهار ات ومعارف المتدربين وفي تكنولوجيا التعلم حتى أصبح من الممكن الآن الوصول إلى أعلى بلى الدرجات العلمية من خلال التعلم عن بعد أما من حيث التطبيق على المستوى المؤسسي يمكن باستخدام

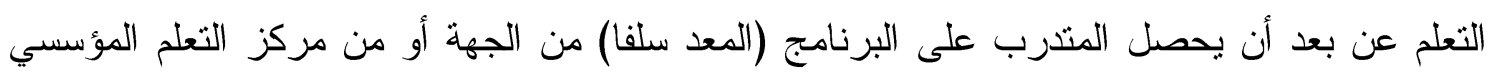
لمساعدته على تطور مهار اته ومعارفه بما يمكنه من أداء وظيفته (Corporate Learning Center) بطريقة أفضل، وذللك من خلال أساليب تعلم حديثة تفاعلية Interactive تزيد من مشاركة المتعلم في التعلم وتقلل من الإحساس بالعزلة والتبعية الذي طالما شعر به المتدرب أو المتعلم وهو يستجيب لأو امر بر امج التعلم عن بعد كأحد العو امل الهامة في تحقيق الهدف من التعليم، وخاصة عندما يظهر المعلمون

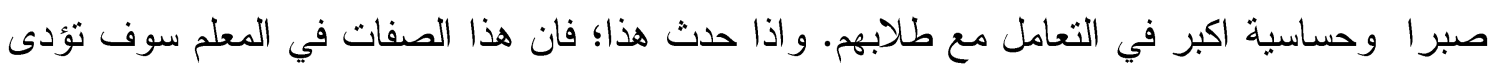
بالطلاب الى تكوين اتجاهات ايجابية نحو التعلم ومن ثم تحقيق توقعات هذا المعلم ـ ولدى المعلمين ايضا توقعات عالية عن انفسه؛ قادرين على تبسير التعلم و استخدام طرق تدريس خاصة بهم، كما انهم يحددون جيدا اهدافهم الشخصية كما يفترض ان ينتقدو انفسهم عند تقيمهم لأنفسهم لنطوير ادائهم فيما 


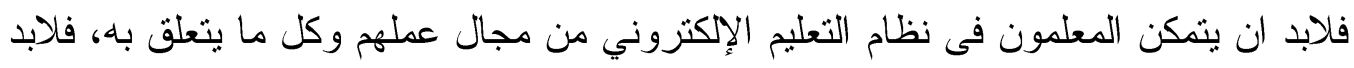

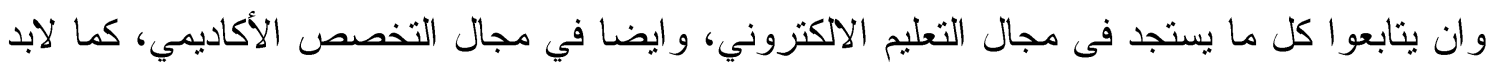

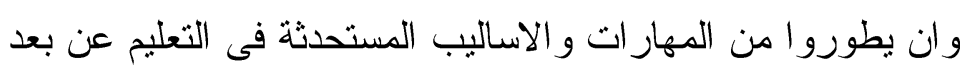

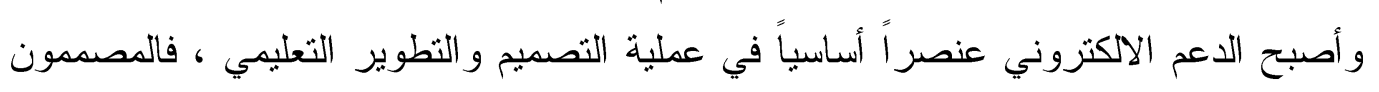

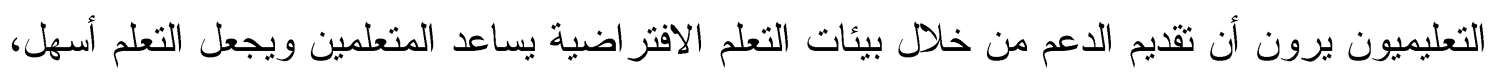

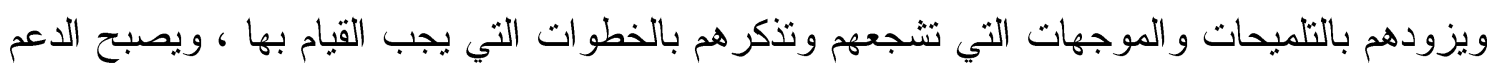
جزءاً لا ينفصل عن مكونات بيئة التعلم ، وبذلك تسمح للمنعلم بتحقيق المهام بطريقة أكثر عمقاً (Quintana,K. , et al ,2002) ويعتبر الدعم الالكتروني آلية فعالة لمساعدة المتعلمين لتوسيع نطاق ومجالات تعلمهم لتتسع

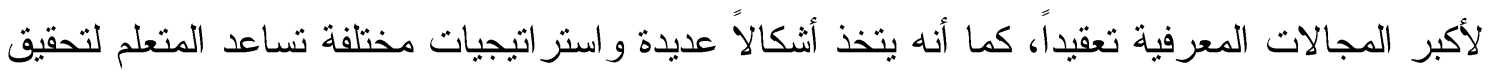

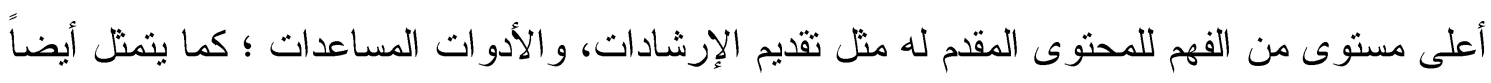

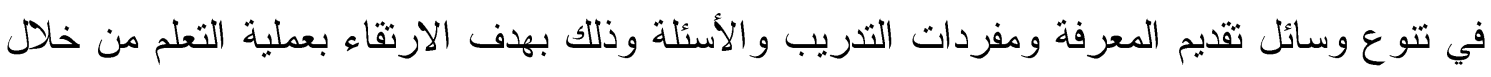

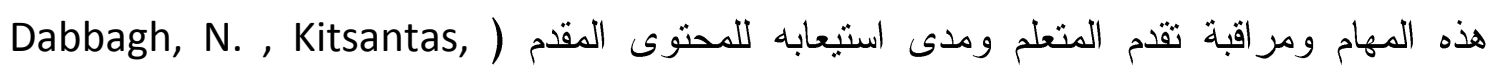
(A.,2005,

وتساعد أنظمة دعم الأداء الإلكترونية في حل المشاكل الغير منظمة و التي تتظلّب تحلبلا و تأليفا

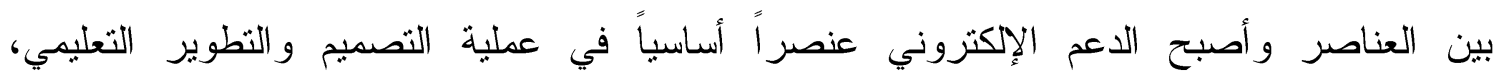

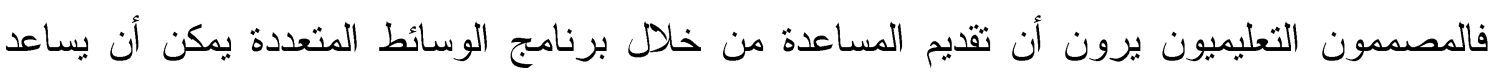

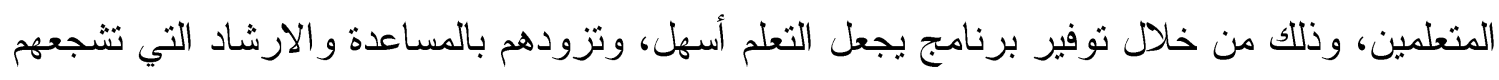
وتذكرهم بالخطو ات التي يجب القيام بها.

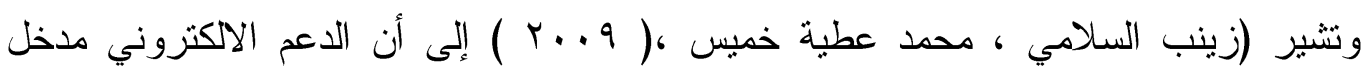

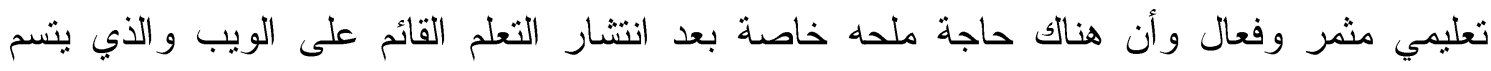

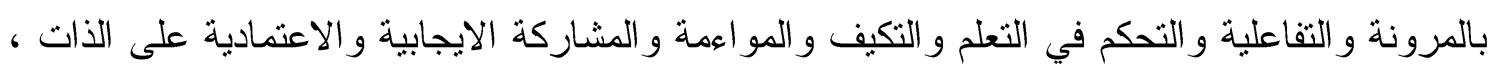

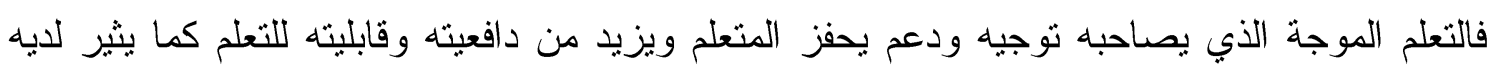

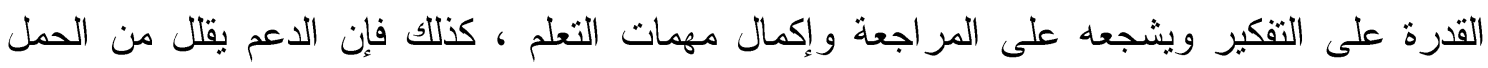

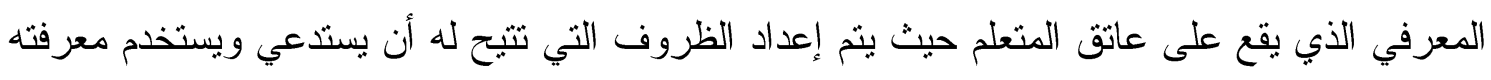

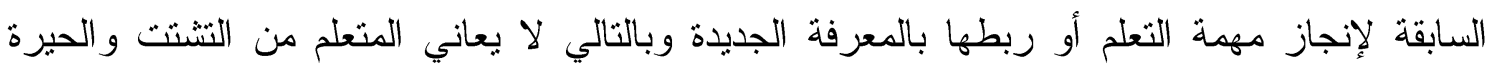

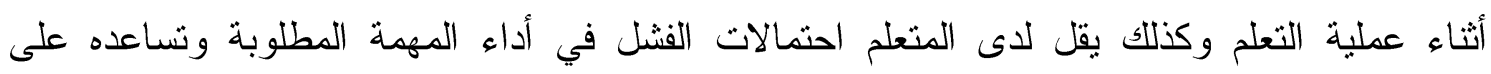
إتمامها معتداً على نفسه حتى يصل إلى مسنوى الكفاءة المطلوب. ويشير Hung, W. \& Chao(2007) أن نظم الدعم الإلكتروني تعد آلية فعالة لدعم التعلم

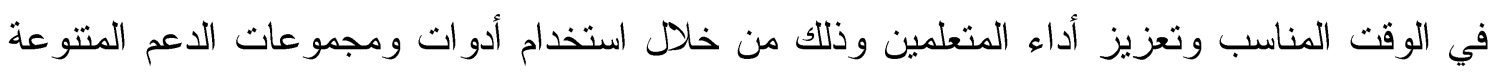

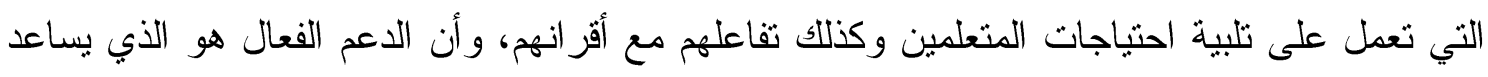


على فهم وتحليل وتطبيق المعلومات والقدرة على توظيفها وذلك من خلال تصميم أدوات الدعم

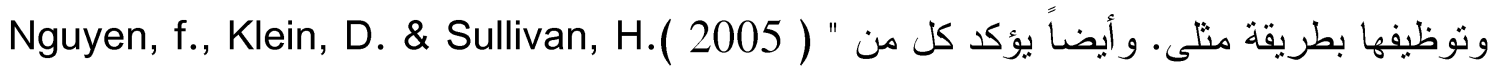

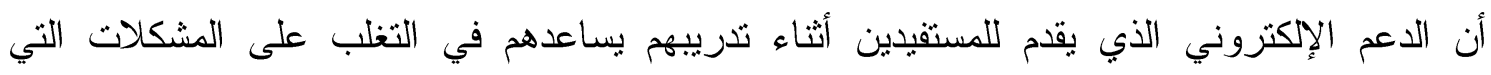

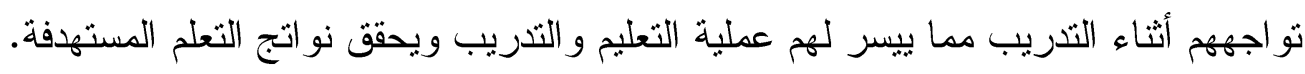

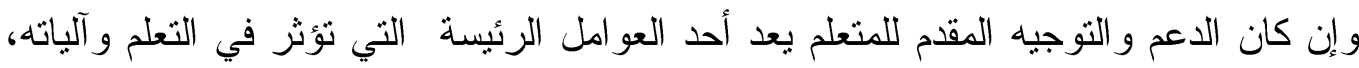

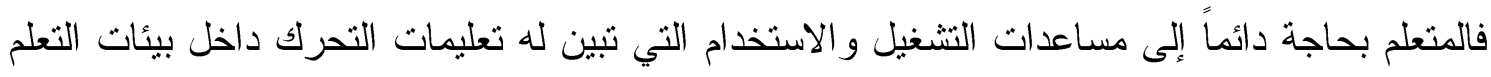

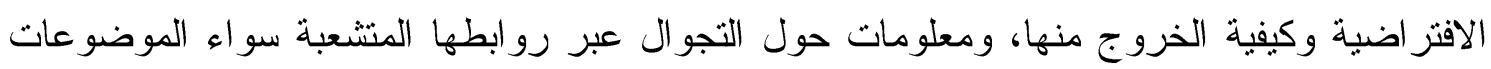

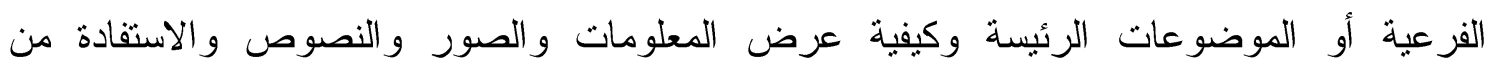

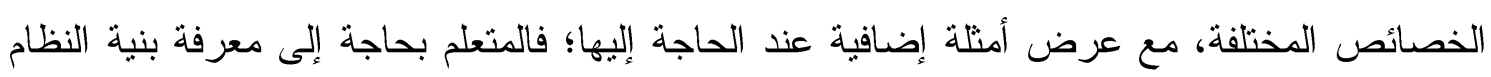
الموجود داخله المحتوى و الرو ابط التى تحيله من جزء إلى جزء داخل هذا المحتوى وهذا لا لا يتحقق إلا

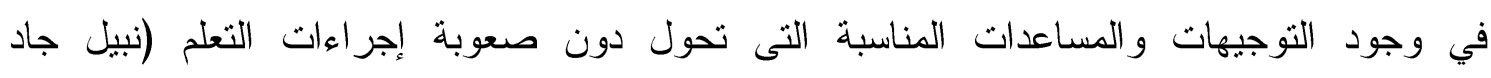

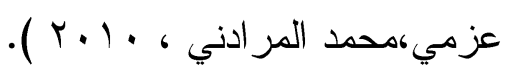

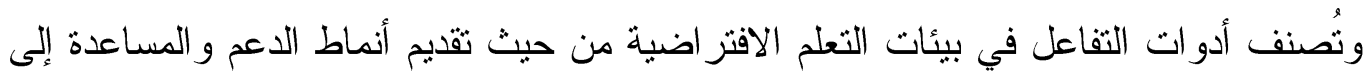

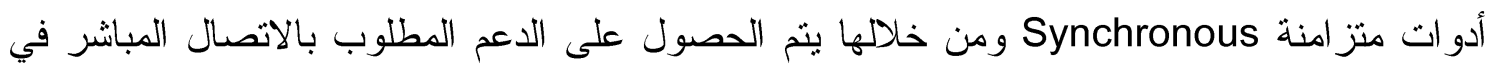

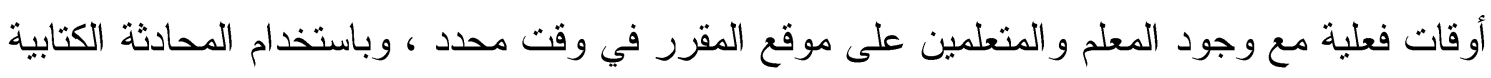

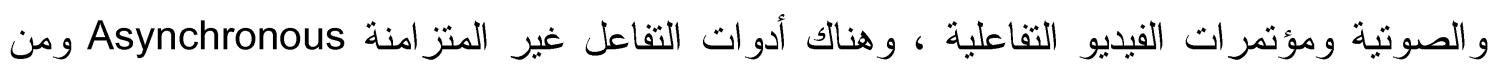

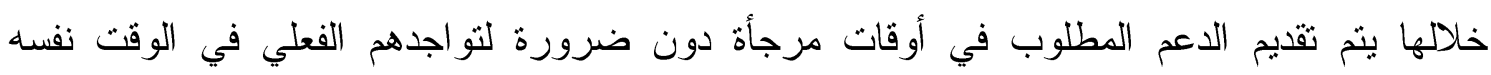

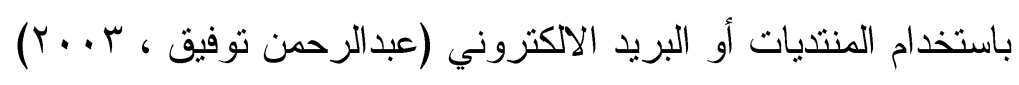

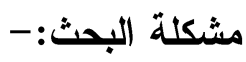

مما سبق يمكن تحديد مشكلة البحث في وجود قصور في تصميم أنماط الدعم ببر امج التدريب

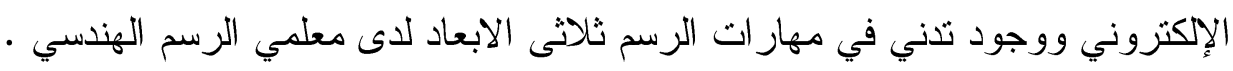

$$
\begin{aligned}
& \text { ويمكن تحديد مشكلة البحث في السؤال الرئيس التالي : :- }
\end{aligned}
$$

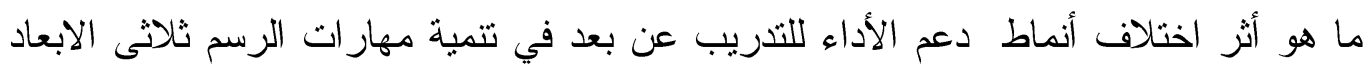

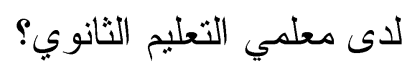
ويتفرع عن هذا التساؤل الأسئلة التالية: 1- ما الاحتباجات التثريبية الفعلية (المعرفية - المهاريه ) لمعلمي الرسم ثلاثى الابعاد بالمرحلة الثانوية ؟ الأبان ץ- ما المعايير التصميمية لبرامج التدريب الإكتروني القائمة على تقديم أنماط الدعم (ثابت/مرن)

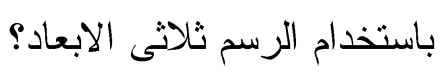
ب- ما التصميم التعليمي لبرنامجي التنريب الإلكتروني في ضوء الابعاده المعايير و الاحتياجات و أنماط الدعم

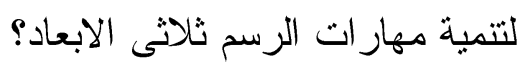


ع- ما أثر تصميم أنماط تقديم الدعم (ثابت/مرن) القائمة على انماط دعم التدريب عن بعد لتتمية

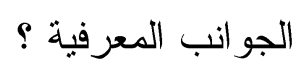

ه- ما أثر تصميم أنماط تقديم الدعم (ثابت/مرن) القائمة على انماط دعم التدريب عن بعد لتتمية

$$
\begin{aligned}
& \text { الجو انب الادائية؟ } \\
& \text { أهداف البحث:- } \\
& \text { بهدف البحث الحالي إلى: }
\end{aligned}
$$

1- التعرف على اثز اختلاف انماط دعم الاداء للتدريب عن بعد في تتمية الجوانب المعرفية لدى

$$
\text { معلمي التعليم الثانوي في مادة الرسم ثلاثى الابعاد. }
$$

r- التعرف غلى اثر اختلاف انماط دعم الاداء للتدريب عن بعدفي تتمية الجو انب الادائية لاى معلمي

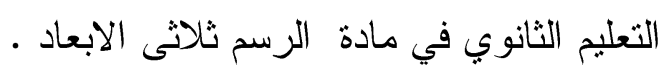

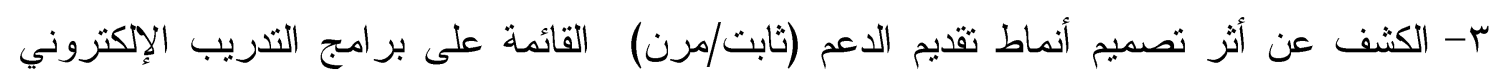

$$
\begin{aligned}
& \text { على التحصيل- الأداء } \\
& \text { أهمية البحث:- }
\end{aligned}
$$

قد يفيد البحث الحالي الفئات التالية:

- مساعدة المعلمين على جودة العملية التعليمية و مسايرة التطورات التكنولوجية في مجال الرسم

$$
\text { ثناعدة: }
$$

- يساعد في النطوير المستمر و التتمية المهنية للمعلمين، وحثنه على متابعة الجديد في التخصص.

$$
\text { القائمون على تصميم البر امج التحليمية التدريبية وتطوير ها: }
$$

- تقديم اتجاهات جديدة في تصميم أنماط الدعم ببر امج التدريب الإلكتروني (ثابت/مرن) القائمة على

$$
\text { تدريس الرسم ثلاثى الابعاد }
$$

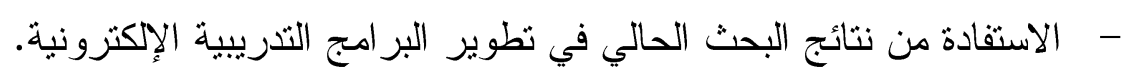

المؤسسات التعليمية:

- - الارتقاء بالمستوى العلمي و التقني للمعلمين في مجال التنريب ، و الذي ينعكس على المنظومة

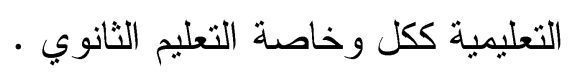

- - مو اكبة النطور ات التكنولوجية و الاتجاهات الحديثة في تدريب المعلمين بالتعليم الثانوي.

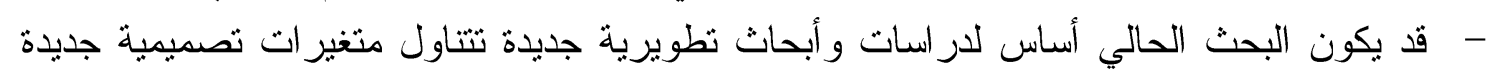

في مجال التثريب الإلكثروني، و أنماط الدعم بها.

$$
\text { حدود البحث : }
$$

1- - عينة من معلمي الرسم الهندسي بالمرحلة الثانوية.

$$
\text { r - بمطين من أنماط ثقديم الدعم (ثابت/مرن) القائمة على التدريب الإلكتروني. }
$$




$$
\text { سوف يتبع البحث الحالي: }
$$

- المنهج الوصفي في تحديد: الاحتياجات التدريبية للمعلمين من مهار ات الرسم الهندسي ، ومعايير التصميم التعليمي الخاصة ببرنامجي التدريب و أنماط الدعم وأهداف التدريب الإلكتروني/ الجزء الخاص بالدر اسة النظرية للأدبيات و البحوث السابقة المرثبطة بالمحاور العلمية التي انثنل عليها

$$
\text { - أدوات البحث:- البهت التجريبي: لدر اسة أثر المتغير المستقل على المتغير التابع. }
$$

1- اختبار تحصيلي لقياس الجوانب المعرفية المرتبطة بمهار ات الرسم ثلاثى الابعاد . r-بطاقة ملاحظة لقياس الجو انب الأدائية المرتبطة بمهار ات الرسم ثلاثى الابعاد .

$$
\text { التصميم التجريبي للبحث: }
$$

اشتمل البحث الحالي على المتغير ات التالية:

المتغير المستقل: Independent Variable

- أنماط تقديم الدعم القائمة على التدريب عن بعد وله مستويان: (مرن/ثابت)

المتغيرات التابعة: Dependent Variables

\begin{tabular}{|c|c|c|c|}
\hline تقويم بعدي & معالجة تجريبية & تقويم قبلي & \\
\hline $\mathrm{O} 2$ & $\mathrm{X} 1$ & 01 & مجمو عة الدعم مرن \\
\hline $\mathrm{O} 2$ & $\times 2$ & 01 & مجمو عة الدعم ثابت \\
\hline
\end{tabular}
- الجو انب المعرفية الخاصة بمهار ات الرسم ثلاثى الابعاد. - الجو انب الأدائية الخاصة بمهار ات الرسم ثلاثى الابعاد.

نوع التصميم التجريبي: البحث الحالي اعتمد على التصميم التجريبي المعروف باسم (تصميم البعد الو احد) ذو مجموعتين تجريبيتين لمتغير مستقل و احد مقدم بنمطين مع القياس القبلي و البعدي (فؤاد أبو بون

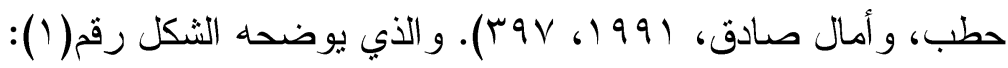

شكل(1) التصميم التجريبي للبحث

حيث : إن:

- م1 - التعرض للتقويم القبلي من خلال تطبيق أدوات البحث قبلياً (الاختبار التحصيلي -بطاقة

$$
\text { الملاحظة). }
$$

- - 
O2: التعرض للثقيم البعدي من خلال تطبيق أدوات البحث بعدياً (الاختبار التحصيلي -بطاقة الملاحظة X2 عينة البحث:-

تتكون عينة الدراسة من مجموعتين ( معلمين ومعلمات )الرسم الهندسي في محافظة الدقهلية بإدارة شرق المنصورة التعليمية، وسيتم اختيار هم بطريقة عشو ائية وسيتم تقسيمهم عشوائي وبالتساوي على المجموعات، وينت نطبيق أدوات القياس قبلياً على المجموعتين، ثم المعالجة التجريبية، وبعد الانتهاء من التجربة يتم تطبيق أدوات القياس بعدياً على المجمو عتين.

$$
\text { فروض البحث :- }
$$

1- يوجد فرق دال إحصائيا عند مستوى دلالة (0. . •) بين متوسطي رثب درجات طلاب المجموعة التجريبية الأولى التي تتعلم من خلال (نمط الدعم الثابت) في النطبيقين القبلي و البعدي لاختبار التحصيل المعرفي لدى معلمي المرحلة الثانوية الصناعية لصالح النطبيق البعدي" r- يوجد فرق دال إحصائيا عند مستوى دلالة (0...) بين منوسطي رثب درجات طلاب المجموعة التجريبية الأولى التي تتعلم من خلال ( نمط الدعم الثابت ) في النطبيقين القبلي و البعدي لبطاقة الملاحظة المرتبطة بمهار ات الرسم ثلاثى الابعاد لدى معلمي المرحلة الثانوية الصناعية لصالح التطبيق البعدي". r- يوجد فرق دال إحصائيا عند مستوى دلالة (0. . ·) بين متوسطي رثب درجات طلاب المجموعة التجريبية الثانية التي تتعلم من خلال ( نمط الدعم المرن ) في التطبيقين القبلي و البعدي لاختبار

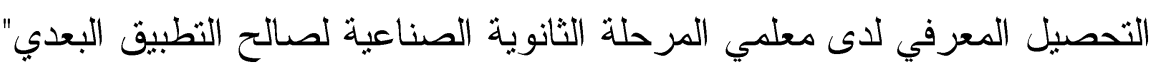
ع- يوجد فرق دال إحصائيا عند مستوى دلالة (0. . .) بين متوسطي رثب درجات طلاب المجموعة التجريبية الثانية التي تتعلم من خلال ( نمط الدعم المرن ) في التطبيقين القبلي و البعدي لبطاقة الملاحظة المرنبطة بمهارات الرسم ثلاثى الابعاد لدى معلمي المرحلة الثانوية الصناعية لصالح التطبيق البعدي". ه- يوجد فرق دال إحصائيا عند مستوى دلالة (0...) بين متوسطي رتب درجات طلاب المجموعة التجريبية الاولى التي تتعلم من خلال ( نمط الدعم الثابت ) و المجموعة التجريبية الثانية التي تثعلم من خلال ( نمط الدعم المرن ) في التطبيق البعدي لاختبار التحصيل المعرفي لدى معلمي المرحلة الثانوية الصناعية". צ- يوجد فرق دال إحصائيا عند مستوى دلالة (0. . •) بين منوسطي رتب درجات طلاب المجموعة التجريبية الاولى الني تتعلم من خلال ( نمط الدعم الثابت ) و المجموعة التجريبية الثانية التي تثعلم من خلال ( نمط الدعم المرن ) في التطبيق البعدي لبطاقة ملاحظة الجانب الادائي لمهار ات الرسم ثلاثى الابعاد لاى معلمي المرحلة الثانوية الصناعية". 


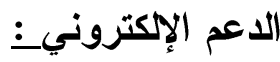

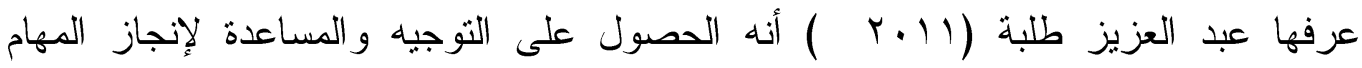
التعليمية في الوقت الفعلي وبشكل موجز ومختصر من خلال استخدام أدو ات الدعم المطروحة.

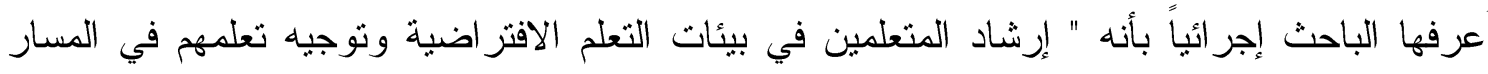
الصحيح نحو تحقيق الأهداف التعليمية ". نمط الدعم الاككتروني:

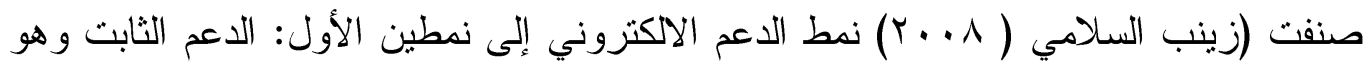

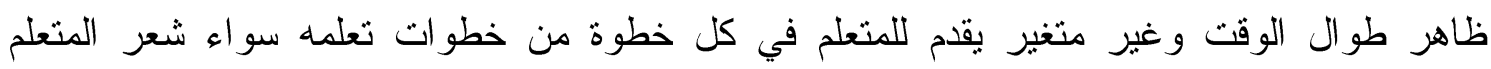

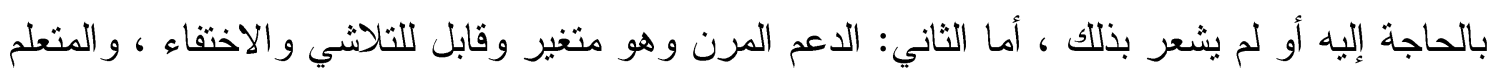

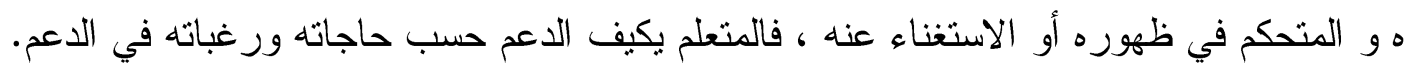

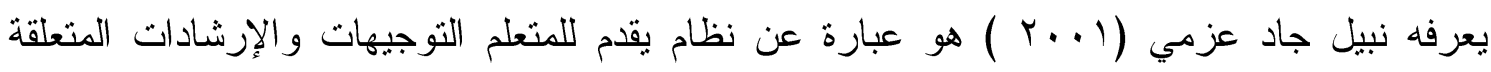

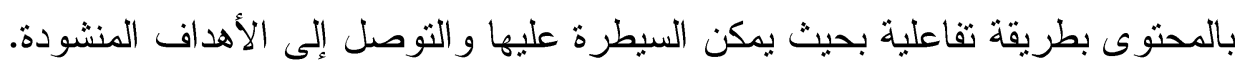

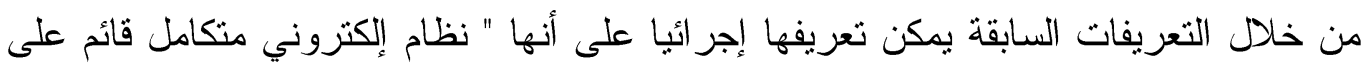

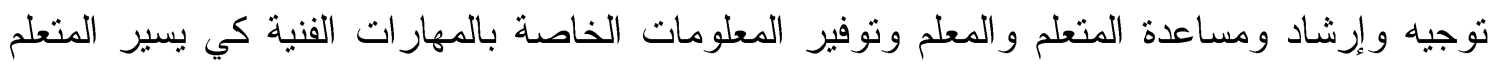
في تعلمه بسهولة ويسر، ويحقق مستوى التمكن المحدد، و الأهداف التعليمية المحددة"

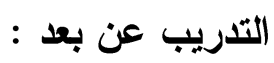

هو نظام تدريب نشط غير نقليدي يعتمد على استخدام مواقع شبكة الانترنت لتوصيل

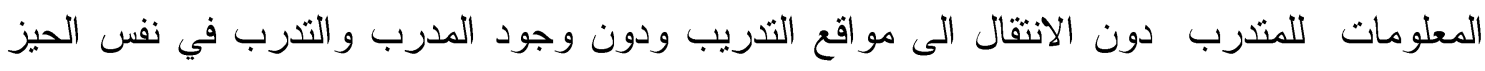

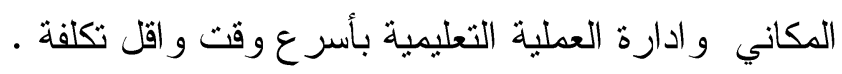

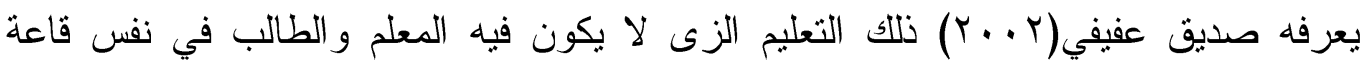

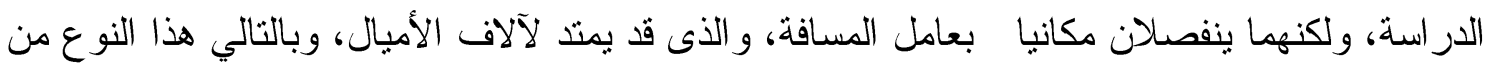

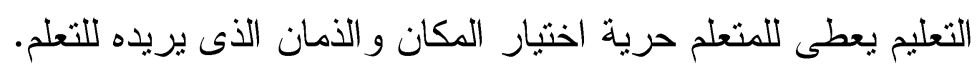

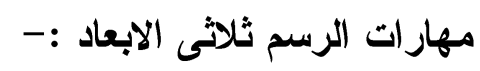

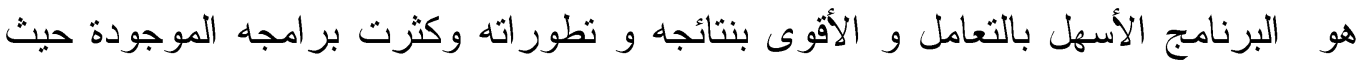
أصبح عالم التصميم ثلاثي الأبعاد في الوقت الحاضر أقرب إلى الحقيقة من الخيال وبعبارة أخرى فهو

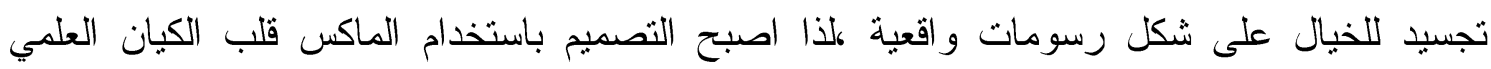

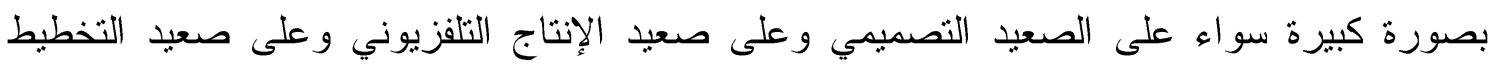

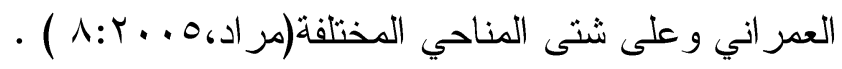

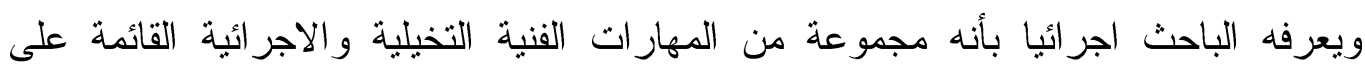
استخدام الادو ات بمهارة و اثقان في رسم الثكل تفصيليا سو اء بالطريقة النقليدية وبالأساليب الاككترونية. 


\section{أنماط دعم الأداء في بيئات التدريب عن بعد لتنمية مهارات الرسم ثلاثى الابعاد المحور الاول: التعليم والتدريب عن بعد:}

يعد التعليم احد الركائز الأساسية التي تقوم عليها الأمم الحديثة، حيث أصبح التسابق بين الأمم الآن يعتمد على امتلاك المعلومات وكيفية توظيفها، و أصبح البحث العلمي هو المجال الذي تثتافس فيه الأمم من أجل اللحاق بأخر تطورات العلم حفاظا على مكانتها بين الأمم، ومن اجل تتمية مجتمعاتها على الأسس العلمية التي تأخذ بيد الأمم إلى الرقى و التقدم، كما شهدت الفترة الماضية تغير ات وتحديات و اضحة في شتى تخصصات التعليم العام والفني الأمر الذي دفع المهنمين بمجالات التعليم إلى إعادة في نظام التعليم القائم وتطويره بما يتو اكب مع التغير ات الحادثة. ويرى حمدي البيطار( ( . . r) أن المستحدثات التكنولوجية أثرت في العملية التعليمية ككل من معلم ومتعلم ومحتوى و أنشطة ووسائط نعليمية، وطرق و أساليب التدريس و التقويم، و إدارة العملية التعليمية، فقد تغير دور المعلم من المعلم الناقل للمعرفة إلى المعلم الذي يساعد المتعلم في بناء المعرفة و أصبح دوره ميسر ا ومسهلا، وموجها، ومرشدا، ومديرا، ومصمما لبيئة التعلم، كما تمركز المهج

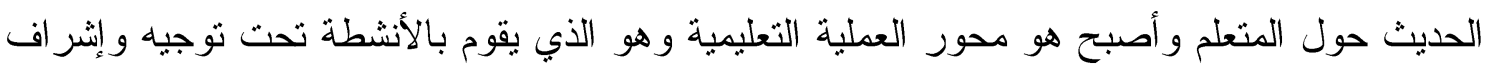
المعلم، كما غيرت المستحدثات من شكل بيئة حجرة الدر اسة التقليدية وحولتها إلى بيئات جديدة مصممة

لتلاعم احتباجات جديدة مصممة لتلاعم احتباجات وميول و استعدادات الأفر اد وخطو هم الذاتي.

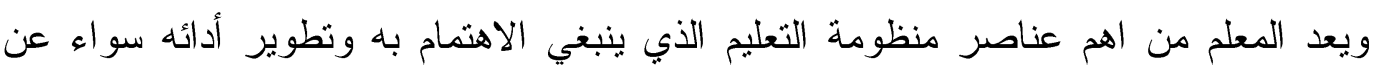
طريق الأنشطة المباشرة في برامج التذريب الرسمية، أو باستخدام أساليب التعلم الذاتي والتدريب المعتمد على الكمبيونز و التدريب المعتمد على الويب مع توفير أنماط الدعم المختلفة في هذه البرامج لإيصال المعلم إلى أقصى ما تمكنه قدر اته و إمكاناته. إن ظروف الحاجة الناتجة عن زيادة الأعداد والتوسع الجغرافي وثقنين المصروفات وضبطها وكذلك أحقية جميع أفراد المجنمع في الانتماء للمؤسسة التعليمية و الحصول على فرصة للتعليم و التثريب وكذللك خصوصية بعض فئات المجتمع، جميع هذه العوامل جعلت من الضروري تبني استر اتيجيات جديدة يمكن الاعتماد عليها في تطوير المجتمعات بشكل عام وبما ينعكس أثره على الدولة وتتمية عناصر القوة فيها سو اء المادية أو البشرية في ظل اقتصاد عالمي.

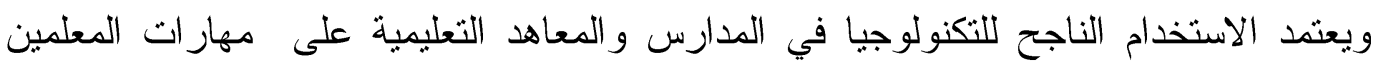
و العاملين الآخرين فيها، وقد أدت زيادة استخدام التكنولوجيا وانتشارها في المدارس و المؤسسات

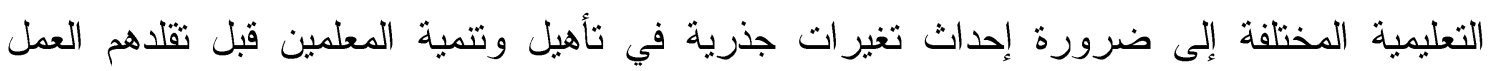
وبعده، كما ساهم أيضا فى إصلاح السياسات التعليمية التي توجه تتمية المعلمين مهنيا للتغيرات المرتبطة بالاستخدام التكنولوجي المكثف دوران أساسيان هما: ـ - الدور الأول يتمثل في تتمية المهارة، حيث يجب أن يتعلم المعلمون و العاملون كيفية تطبيق التكنولوجيا بفاعلية فى التذريس و التعلم. 
- الدور الثاني يوضح أن التكنولوجيا ليست إلا وسيلة تتمية المهار ات، حيث يمكنها إتاحة المعلومات

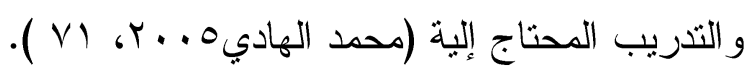

ويمثل الثدريب عبر الإنترنت نافذة متجددة لتقديم برامج وأنشطة التنمية المهنية ذات الكفاءة العالية مع تحقيق التفاعل بين المدرب و المتدرب إلى جانب تطوير محتوى التدريب باستمرار . (هشام

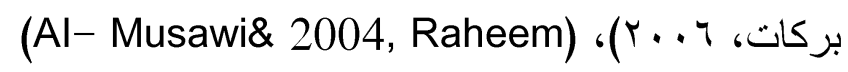
و أمام أهمية تحقيق النمو المهني للمعلم يصبح من الضروري تتظيم برامج وأنشطة للتنمية المهنية باستمر ار لجميع المعلمين باختلاف مستوياتهم المهنية وتخصصاتهم العلمية، وهنا تصبح مر اكز التثريب عاجزة عن استقبال آلاف المعلمين في برامج تدريب متتوعة مستمرة ذات كفاءة عالية، لذا يصبح "التعلم عن بعد" فرصة كبيرة لتقديم بر امج تدريب متتوعة ومتجددة باستمر ار وبتكلفة اقتصادية

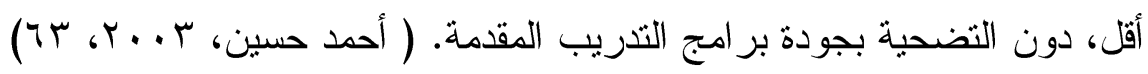
وفى ضوء ماتقدم يتتاول الباحث مفهوم التذريب عن بعد بالتفصيل فيما يلي.

\section{مفهوم التدريب عن بعد:}

إحدى الطرق الحديثة المستخدمة في التدريس والتي تختلف عن التعليم التقليدي الذي يتطلب وجود علاقة مباشره بين الطلبة و المدرسين ضمن مكان محدد، وقد بدأ استخدام تعبير التعليم عن بعد، في نهاية القرن التاسع عشر، وذللك لفتح الفرص أمام الأفراد للار اسة بغض النظر عن مواقعهم

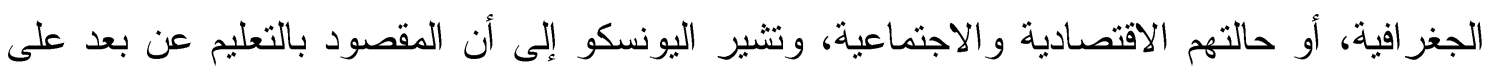

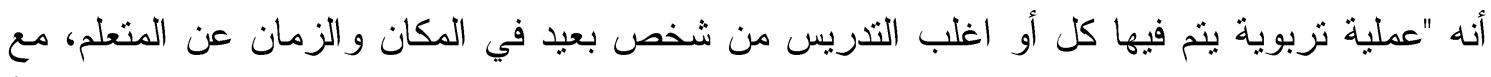
التأكيد على أن أغلب الاتصالات بين المعلمين و المتعلمين تتم من خلال وسيط معين سو اء كان إلكترونياً أو مطبو عاً". (UNESCO, 2002, 22)

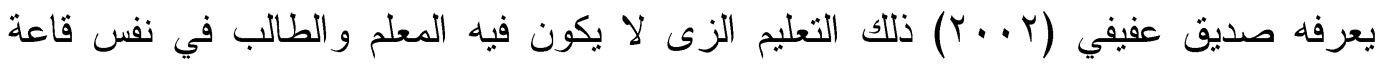
الدر اسة، ولكنهما ينفصلان مكانيا بعامل المسافة، والذي قد يمتد لآلاف الأمبال، وبالثالي هذا النوع من التعليم يعطى للمتعلم حرية اختيار المكان و الزمان الذي يريده للتعلم. كذلك يرى "ستون دافيد"(Daviad, 2002) أن التذريب عن بعد: هو عبارة عن عملية ديناميكية

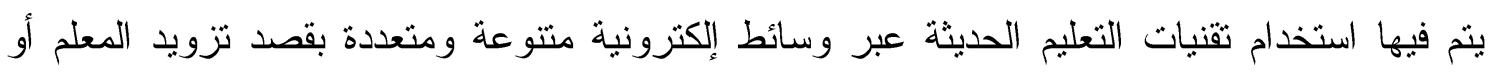
المتدرب بمجموعة من المهار ات و الخبرات و المعارف المتتوعة ولتخطي بالحدود الزمنية بين المعلم و المتعلم.

بينما يعرف أحمد محمد سالم (ع . . ، YAN) التثريب عن بعد بأنه تقديم المحتوى التعليمي

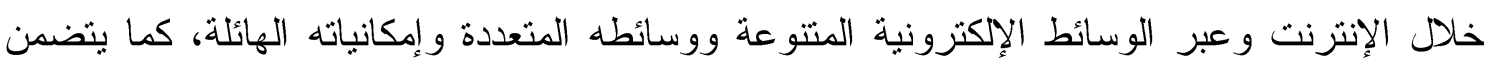
استخدام الإنترنت كوسط (بيئة) للتدريب بأسلوب مثزامن وغير مثز امن، ينت من خلال التفاعل بين المدرب و المتدربين. 
بينما در اسة محمد جابر (7 . r) و هدفت إلى تحديد فاعلية برنامج مقترح للتنريب بالإنترنت

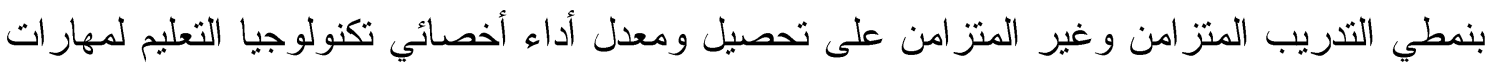
استخدام برامج الحاسوب وتحديد اتجاهاته نحو التدريب بالإنترنت وقد أكدت الدراسة على فاعلية البرنامج المقترح بغض النظر عن نمط تقديمه في زيادة التحصيل. ويرى الباحث من خلال استعراض التعريفات السابقة للتثريب الاككتروني وجود اتفاق بين تلك التعريفات على أن العملية التفاعلية التي تشمل مدخلات ومخرجات وعمليات تتم من خلال آليات الاتصال الحديثة للتغلب على حدود الزمان و المكان وهو نمط للتذريب عبر الشبكة للوصول للمندرب في أى مكان وفى الوقت الملائم له ويساعد في التغلب على معوقات التدريب التقليدي عبر الاستفادة من ون إمكانات التكنولوجيا الحديثة في توصيل المحتوى التدريبي.

أهداف التدريب عن بعد:

تتمثل أهداف التدريب عن بعد فى مساعدة المؤسسات لتعديل الطرق التقليدية في تتمية مو اردها البشرية وبحيث يتم تهيئة المتدربين لإنتاجية أكبر في مجتمع المعرفة باستخدام الثقنيات المعاصرة أثناء التذريب و إعدادهم لتوظيفها بصورة فعالة في سوق العمل، كما يهدف التذريب عن بعد إلى مواكبة التحديث المنسار ع في مناهج التدريب وتصميمها ومحتو اها و أساليبها فيتيح فرص مرنه وميسرة للقيام بذلك باستمر ار بو اسطة بيئات التذريب الافتز اضية. (على الموسوي، ـ ( • ب).

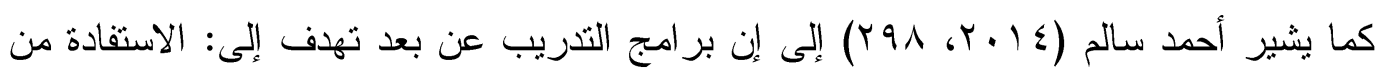
تقنيات التكنولوجيا الحديثة فى تقليل أعباء التدريب سواء كانت مادية ومعنوية، التغلب على معوقات التدريب التقليدي عن طريق خلق بيئة تعليمية تفاعلية من خلال التقنيات الاككترونية الجديدة، دعم عملية التفاعل بين المعلمين و المتعلمين من خلال تبادل الخبرات بالنقاشات الهادفة، إكساب المعلمين المهار ات التقنية لاستخدام التقنيات التعليمية الحديثة، نمذجة التعليم وتقديمه بصورة مثلى، إيجاد شبكات تعليمية لتنظيم و إدارة عمل المؤسسات التعليمية، عادة صياغة الأدوار بما يتو افق مع مستجدات الفكر التزبوي وكذلك تتاقل الخبرات التربوية بين المعلمين و المدربين و المشرفين من خلال إيجاد قنوات اتصال و ونتديات.

تعتبر عملية تحديد الأهداف وصياغتها من أهم العمليات التي يقوم عليها التدريب عن بعد نجد أنها تشكل نقلة نوعية في التذريب؛ لأن الهدف إذا تم تحديده بدقه فإنه بيسر عمليات الملاحظة و القياس و التقويم. ويسع التدريب الإكتروني إلى تحسين أداء المتعلم، ومر اعاة الفروق الفردية بين المتعلمين، و استخدام استراتيجيات وأساليب تدريسية حديثة، نجد أن التدريب الإكتروني احتل مكانة كبيرة في تدريب المعلمين أثناء الخدمة وتطوير التعليمية، ومو اكبة المعلمين للمستجدات في حقول المعرفة ذات

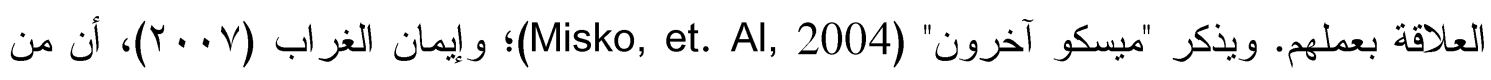

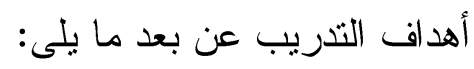
() استكمال تأهيل المعلم في المادة إذا كان هناك قصور في إعداده لمهنة التعليم في مرحلة معينة. 
r) تتمية الخبرات والمهارات و الرغبة في استخدام قدرات المعلم استخداما جيدا من خلال تزويد المعلمين بالمعلومات و المستجدات العلمية و التقنيات الحديثة.

ب) تتيح للمتدرب ثقديم أشكالاً متعددة من أنماط الدعم الإككتروني المختلفة بحيث ثعمل على ثقديم أشكال متعددة للتوجيه و المساعدة أثناء التشريب.

ع) توفير التعلم الفردي، إذ يمكن للمتعلم أن يتعلم بطريقة فردية، وأن يختار المحتوى المناسب له له ويشعر أنه في حاجة ماسة إلبه مع القدرة على الثقبيم الذاتي.

ه) تطوير دور المعلم في العملية التعليمية؛ حتى يتو اكب مع التطورات العلمية و التكنولوجية المستمرة و المتلاحقة.

7) أن يجعل المتدرب يشعر بضرورة لأهمية التدريب وينى التقة و الفهم التام للعملية التذريبية.

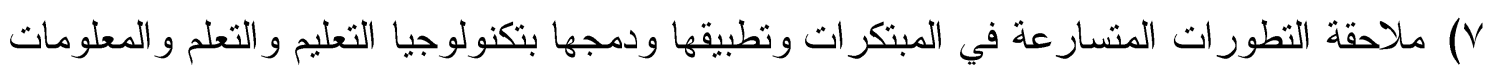
و الاتصالات و التكنولوجيا الرقمية.

إعداد جيل من المعلمين و المتعلمين قادر علي التعامل مع التقنية ومهار ات العصر و التطور ات الهائلة التي يشهدها العالم. خصائص التدريب عن بعد:

يعتبر التدريب عن بعد أحد المستحدثات التكنولوجية في تدريب المعلمين و المعلمات،حيث يتم تدريبه على كيفية توظيف أحدث الأساليب التدريسية و الوسائل التكنولوجية في العملية التعليمية ،حيث يحتوى على ايجابيات ينفرد بها عن أي نظام تدريبي آخر .

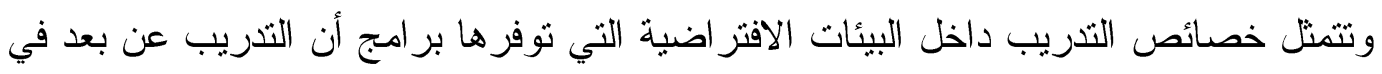

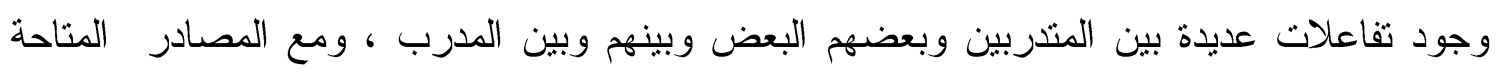

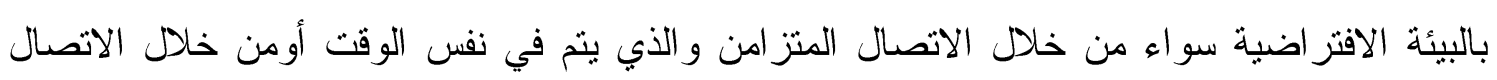
غير المتز امن و الذي لا يتطلب وجود جميع المشاركين في البيئة الافتر اضية في وقت و واحد ويتم من خلال أدو ات عديدة مثل البريد الالكتروني و المنتديات الالكترونية و النشارك في المصادر المتنوعة ،كما يمكن تسجيل كافة الجلسات التي تعقد بالبيئة الافتز اضية التي توفرها برامج التدريب عن بعد و إعادة

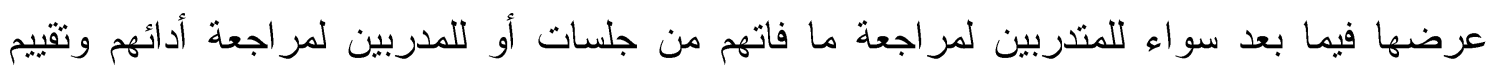

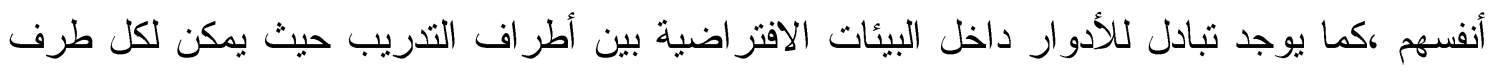
القيام بدور الميسر وتقديم الدعم و التوجيه والإرشاد والتغذية الراجعة من خلال التقاعل المباشر فيما لتابن بينهم ،بالإضافة إلى تبادل خبر ات المندربين داخل الجلسات الافتر اضية و التي تتم لمجتمع البيئي الشعور بالتز ابط والانتماء لمجتمع البيئة الافنز اضية وزيادة فرص التعلم لجميع المشاركين وتحقيق متعة

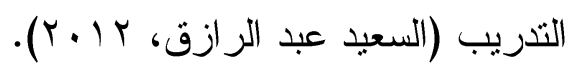


أنواع التدريب عن بعد:

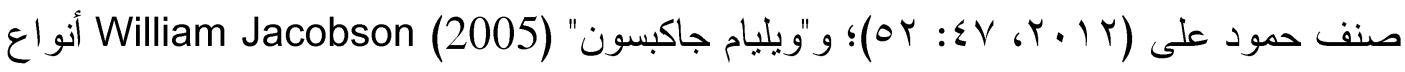
التندريب عن بعد إلى: التى

1) التدريب الإكتروني المعتمد على الحاسب الآلي.

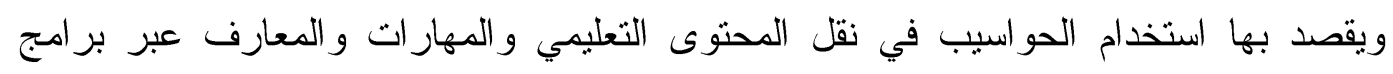

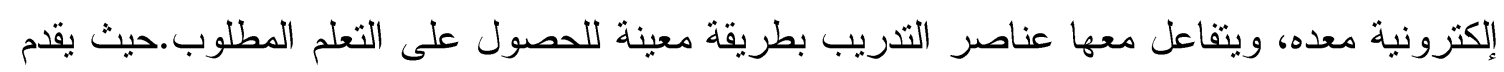

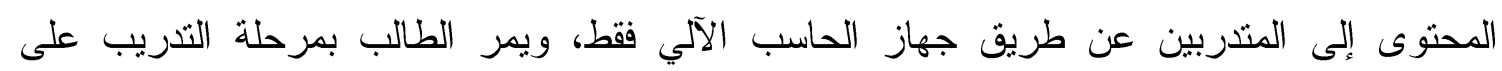

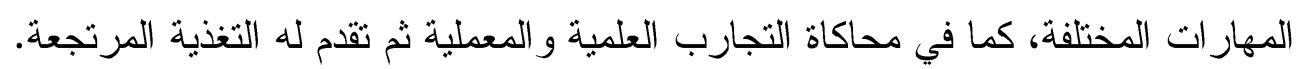
r التدريب الإكتروني المعتمد على شبكة الإنترنت. ويتم من خلالها تبادل المعلومات ما بين مجموعة الحواسيب الإنترني المعروفة، و التي تتصل فيما بينها عن طريق الإنترنت، حيث وجود بيئة افتز اضية تفاعلية. يعتمد التثريب عن بعد على تقديم المحتوى و التو اصل و التفاعل باستخدام أنماط التقديم المناسبة

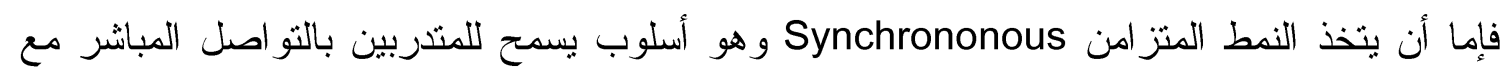

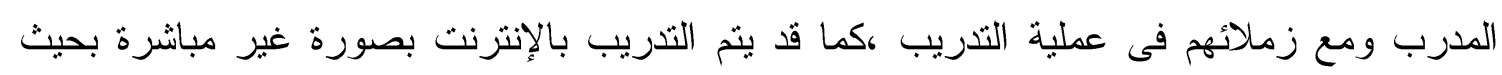

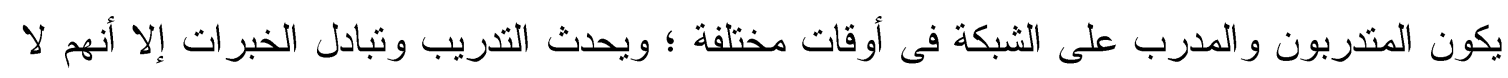

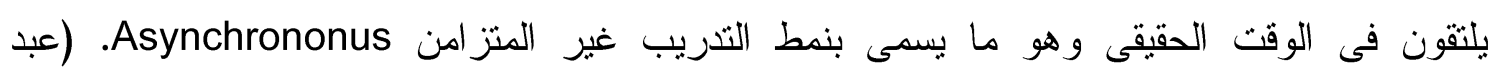

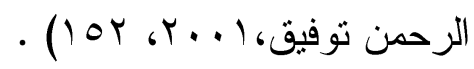

المحور الثاني: الدعم الإكتروني في بيئات التتريب عن بعد: مفهوم دعم الأداء الأكتروني: الأبم الأكتروني حيث سيتناول الباحث فيما يلي مفهوم دعم الأداء الإكتروني: برى "فرنان دو ولويس" (Fernando, \&Luis, 2000) إن الدعم عملية تعليمية تقدم للمتعلم إطارا مؤقتا للعمل إثناء نعلمه يساعده في تتمية مهار اته ودافعتيه ويشجعه على المشاركة في بناء

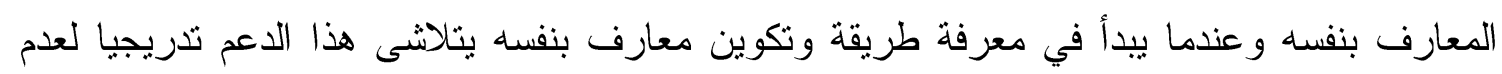
حاجته إليه.

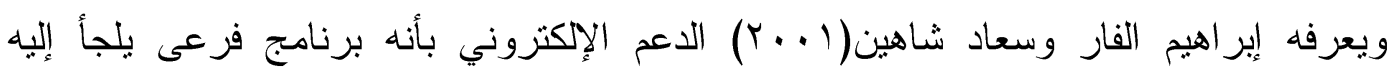
المتعلم لتعلم مفهوم غامض أو مهارة ناقصة ليستكمل بعدها تعلم الوحدة التعليمية المطلوبه.

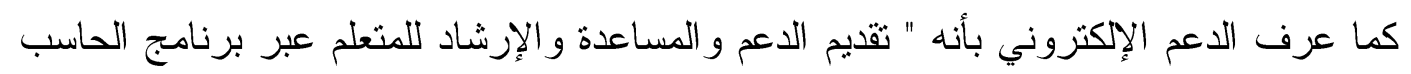

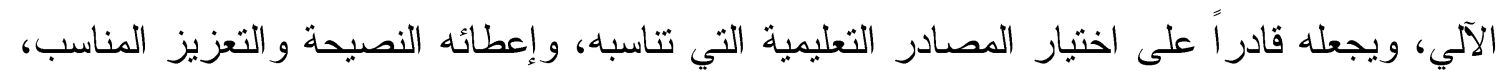

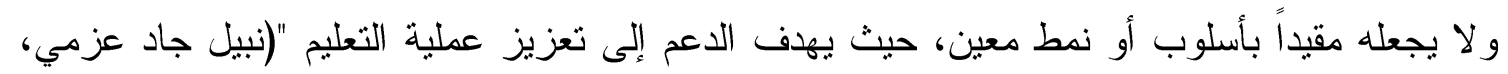


و عرفه آن وبنز ام (Bertram\&Ann 2002) بأنه قدر من المعلومات يقدم للمتعلم عندما يكون في حاجة إليه و هذه المعلومات قد تكون مستمدة من موضوع التعلم أو مرثبطة به. خصائص الاعم الاككتروني: تحدد زينب السلامي، محمد عطية خميس (9 . . Y، ب () خصائص الاعم الاككتروني على النحو التالي: 1- المساندة والدعم Support: حيث يتم تقديم الدعم المطلوب للمتعلم حتى يتمكن من أداء المهمة التعليمية بمفرده معتمداً على نفسه.

ץ- الاختفاء التدريجي Fading: يُعد الاختفاء خاصية هامة من خصائص الدعم الالكتروني وهو

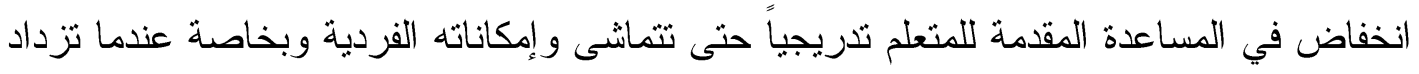
قدرته على التعلم" فكلما زادت قدرة المتعلم التعليمية انخفضت كمية المساعدة المقدمة. ب- التشخيص أو التقدير المستمر:Ongoing Diagnosis or Assessment: يُعد الثقدير المستمر لمستوى فهم المتعلم من خصائص الدعم الالكتروني ، وهذا يتطلب ليس فقط معرفة المهمة ومكوناتها و الأهداف المر اد تحقيقها ؛ و إنما المعرفة المستمرة بقدر ات المتعلم أثثاء التقدم في لئي عملية التعلم ، وبالتالي يُقدم للمتعلم أساليب و استز انتيجات مناسبة لدعمه ومساعدنه. الاعم الالكتروني مؤقت: حيث بستخدم لمساعدة المتعلم على القيام بمهام معقدة لبس في استطاعته إنجازها بطريقة صحيحة ، ويتم إز الة الدعم عندما يشعر المتعلم بعدم الحاجة إليه أو عندما يصل لمستوى التمكن المرغوب ؛ فهنا يجب إخفاء الدعم حتى لا يعيق عملية التعلم. يعتبر الدعم الإلكتروني ضروري لتحفيز الطلاب في العملية التعليمية، حيث تساعدهم على أداء مهامهم، فالمتعلمون من الممكن أن يصلو ا إلى مرحلة الإحباط و الملل وفقد الدافعية والثعور بالفشل عند مو اجهة المشكلات المعقدة فالدعم والتوجيه و الإرشاد مطلب ضروري وحيوي لدعم المتعلمين للوصول إلى مستويات أعلى من التعلم حيث يرى كلا "ر اييولد" (Raybould,1991,5)؛ و "مارى" Mary)

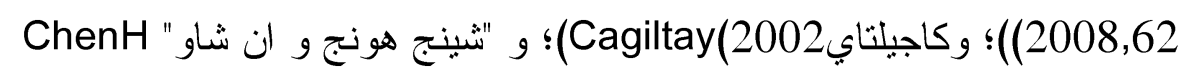
أنواع الدعم الاككترونى:

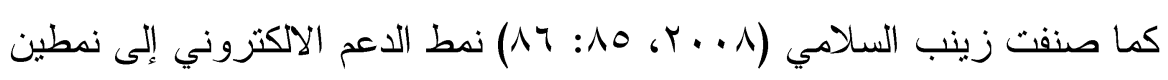
ا- الدعم الثابت: وهو ظاهر طو ال الوقت وغير منغير يقدم للمتعلم في كل خطوة من خطوات تعلمه

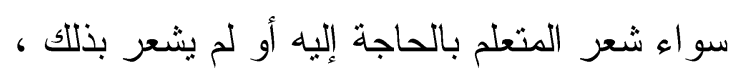

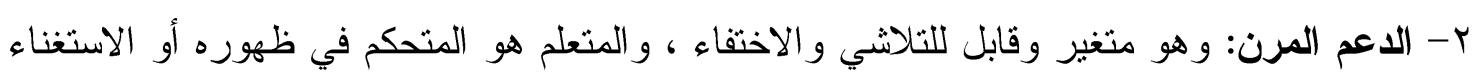

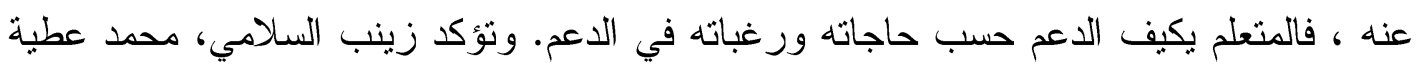

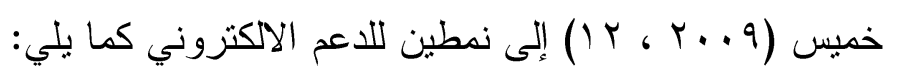

الاعم الثابت Stable Supporting: يتسم الدعم في هذا النمط بأنه ثابت وغير متغير وظاهر طو ال الوقت حيث يُقدم للمتعلم في كل خطوة من خطوات تعلمه المساعدات و التوجيهات التي 
يشعر المصمم التعليمي للبرنامج أن المتعلم قد يكون في حاجة إليها ، وهي بذللك تكون ظاهرة طوال

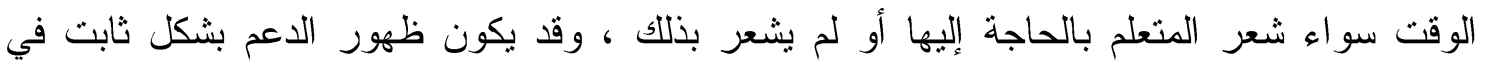

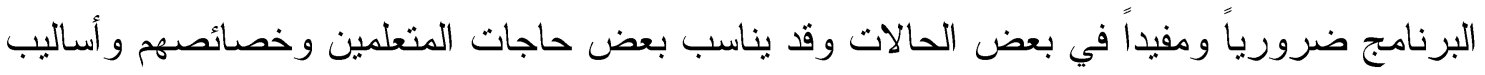
تعلمهز ، ولكند قد لا يناسبهم في حالات أخرى.

الاعم المرن Adaptable Supporting : يتسم الدعم في هذا النمط بأنه متغير وقابل

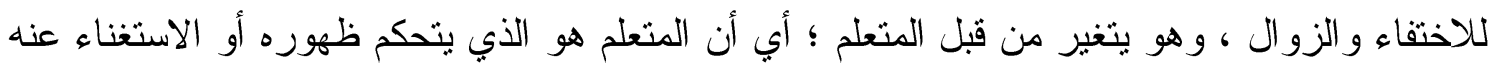

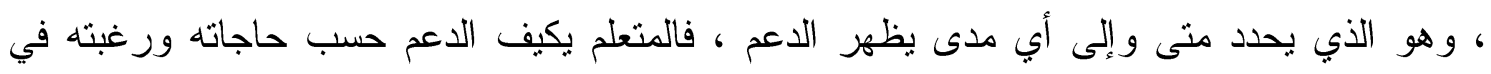

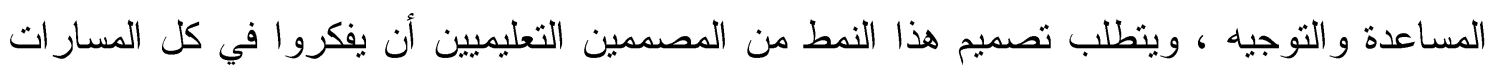

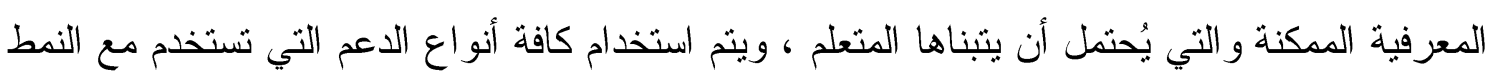

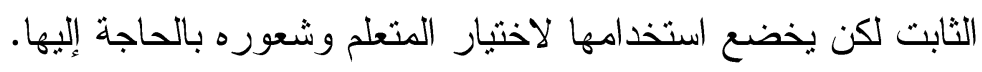

$$
\text { المحور الثالث مهارات الرسم ثلاثى الابعاد. }
$$

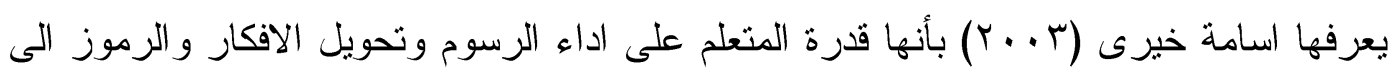

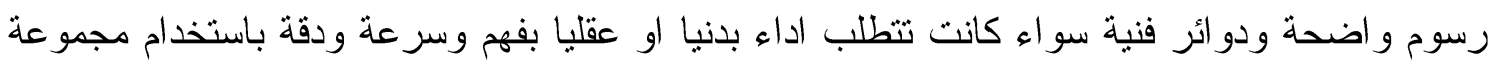

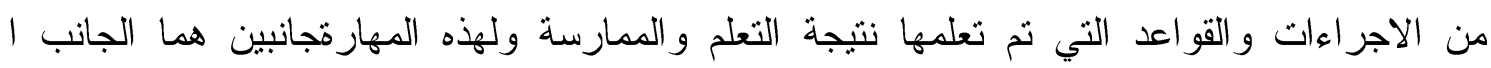

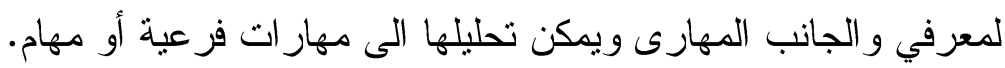

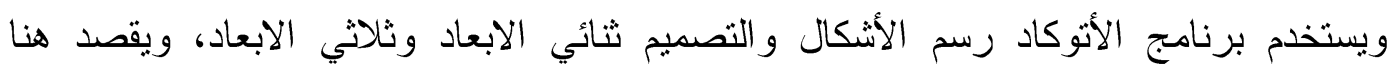

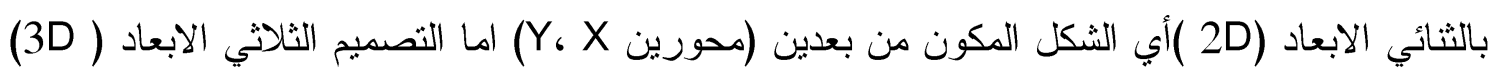

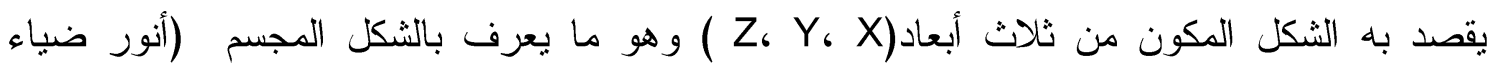
$\cdot\left(r \cdot \Lambda_{6}\right.$

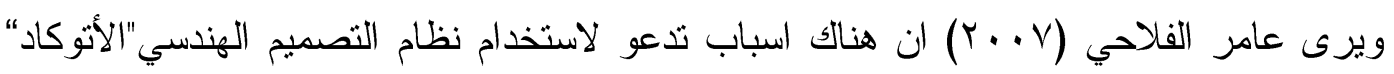
منها: 1) زيادة إنتاجية المصم : وهذا يتحقق بتقليل الوقت الازم للتركيب و التحليل وانجاز الرسومات

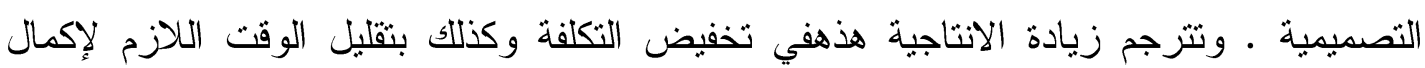

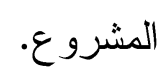

r) تصسين نوعية التصميم :أن نظام التصميم بالكمبيوتز يتيح للمصمم إنجاز تحليلات عميقة ودقيقة

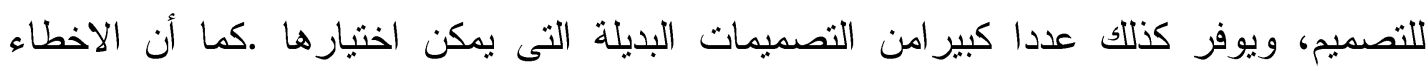

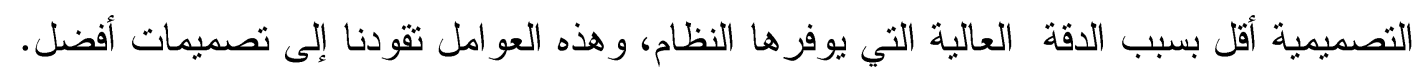

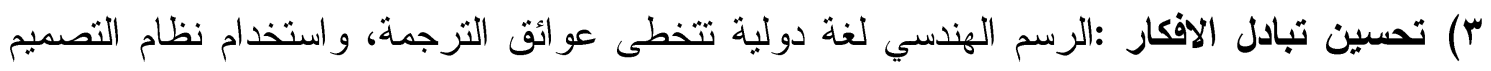

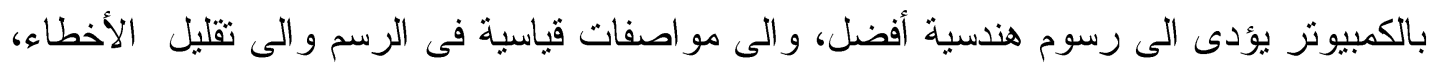

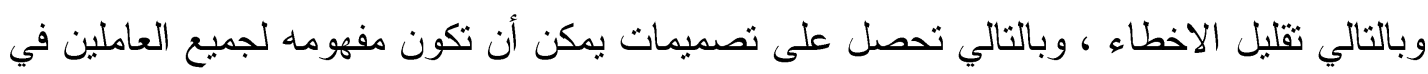
حقول الهندسة بغض النظر عن لغاتهم. 
توفير بيانات تكون قاعدة للتصنيع :

عند تكوين الرسم لمنتج ما (وضع الابعاد على المنتج وأجزائه و تحديد قوائم المواد ومواصفاتها....الخ) تثوفر بيانات كثيرة يمكن استخدامها في عملية التصنيع. يعد الهدف الأساسى للبحث الحالي هو إعداد قائمة بالمعايير التصميمية الخاصة بأنماط ثقديم الدعم القائمة على التنريب عن بعد و التي لها مستويان وهما (مرن/ثابت) لتنمية مهار ات الرسم الهندسي، لذا قام الباحث بمر اعاة الدقة البالغة فى إعداد ثلك القائمة، و التأكد من حسن صياغتها وشمولها للمعايير الاساسية واللامة، مع مراعاة أن تكون جميع المعايير مشتقة من نتائج البحوث العلمية السابقة، وبناءاً علي ذلك تم إعداد وضبط قائمة المعايير الخاصة بأنماط تقديم الدعم القائمة على التدريب عن بعد و التي لها مستو يان و هما (مرن/ثابت) لتتمية مهار ات الرسم الهندسي لدى معلمي التعليم الثانوي الصناعى.

وفيما يلى الإجر اءات التى اتبعها الباحث لإعداد هذه القائمة وضبطها:

\section{ا - تحديد الهُف من القائمة:}

استهدفت هذه القائمة إعداد وضبط قائمة المعايير التصميمية الخاصة بأنماط تقديم الدعم القائمة على التّريب عن بعد و التي لها مستويان وهما (مرن/ثابت) لتتمية مهار ات الرسم الهندسي لاى معلمي التعليم الثانوي الصناعى، ولتحقيق هذا الهدف نم اتباع مجموعة الخطو ات التالية: أ- إعداد الصورة الأولية للقائمة:

حيث قام الباحث بناءً على ما ثم استعر اضه فى الفصول السابقة بصياغة قائمة بمعايير أنماط تقديم الدعم القائمة على التدريب عن بعد و التى يتم فى ضوئها تنمية مهار ات الرسم الهندسي لاى معلمي التعليم الثانوي الصناعى وتم تحديد هذه القائمة من خلال:-

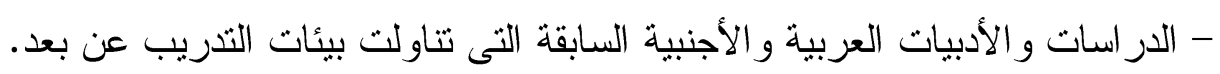
- معايير تصميم انماط الدعم العالمية. - خبر اءو ومتخصصى تكنولوجيا التعليم.

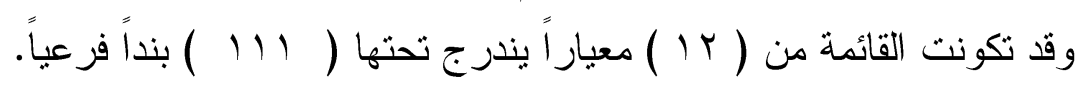
ب- التحقق من صدق القائمة:

للتحقق من صدق القائمة نم عرضها على مجموعة من الخبر اء و المتخصصين فى (تكنولوجيا التعليم- مناهج وطرق التنريس- الهندسة) للتأكد من أهمية كل معيار ومدى ارتباطه بالمحور الرئيسى، وقام الباحث بحساب نسبة اتفاق السادة المحكمين حول أهمية كل معيار ومدى ارتباطه بالمحور

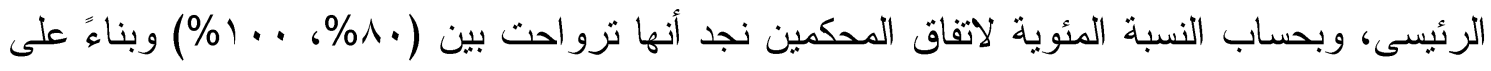
ذلك تم استبعاد مجموعة من المعايير التى تقل نسبة إتفاق السادة المحكمين عليها عن •^^\%، وإجراء

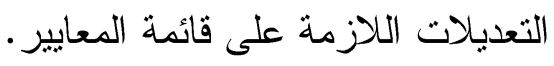


ج- إعداد الصورة النهائية للقائمة:

بعد الانتهاء من ضبط القائمة و النحقق من صدقها، توصل الباحث إلي قائمة المعايير فى

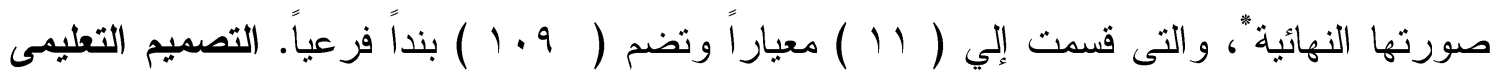
لأنماط تقديم الدعم القائمة على التدريب عن بعد و التي لها مستويان وهما (مرن/ثابت):

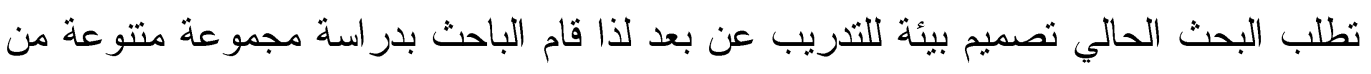

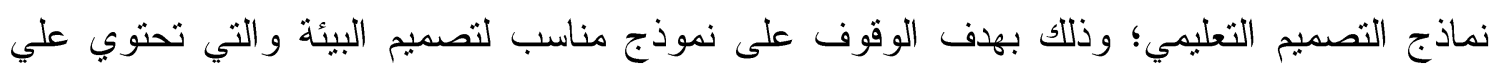

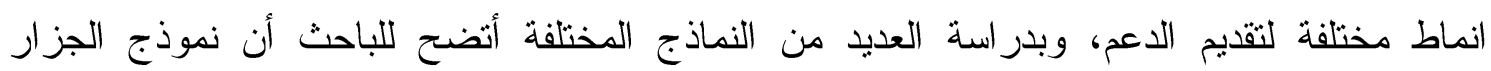

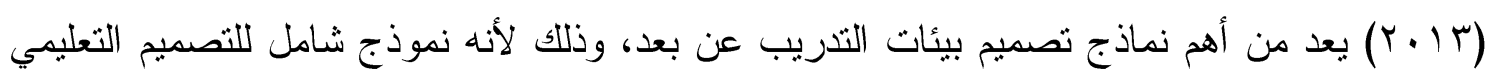

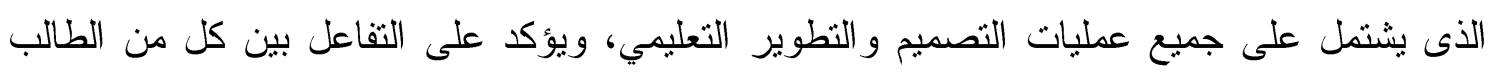

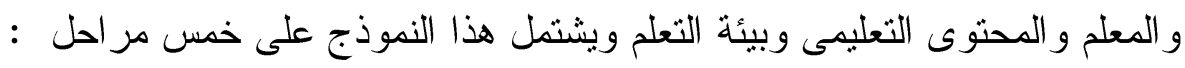


(العدد الرابع) ديسمبر 1 • •

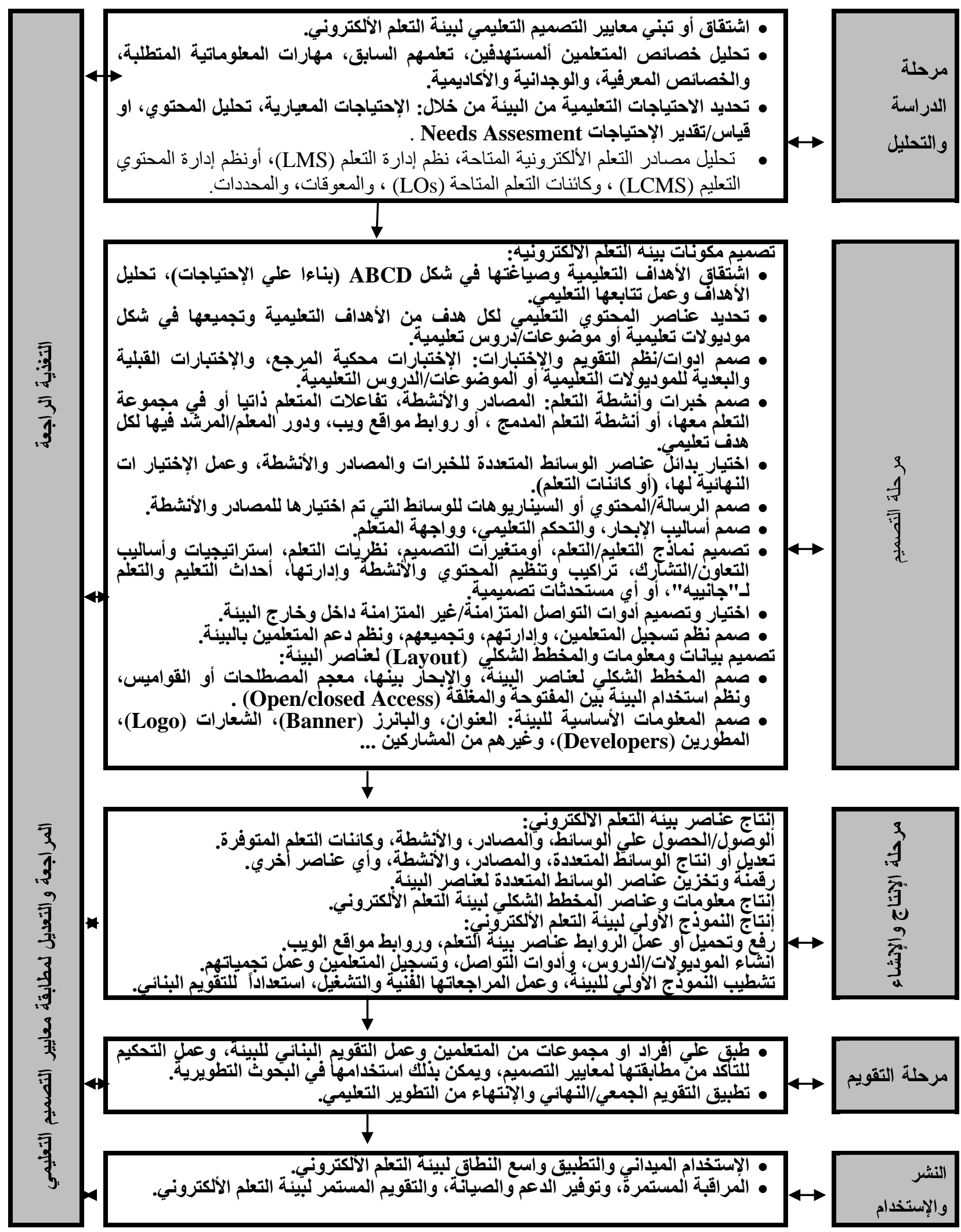


إجراء التجربة الميدانية للبحث:

تمّ تتفيذ نجربة البحث وفق الخطوات الثنالية:

$$
\text { - إنتيار عينة البحث: }
$$

تم اختيار عينة البحث من معلمي المرحلة الثانوية الصناعية بمدرسة سلامون الثانوية

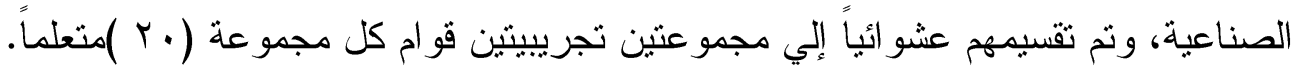
r - ب تطيق أدوات البحث قبلياً:

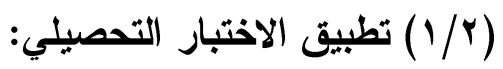

حيث قام الباحث بالتطبيق القبلى للاختبار التحصيلي المعرفي لمهارات الرسم الهندس، علي

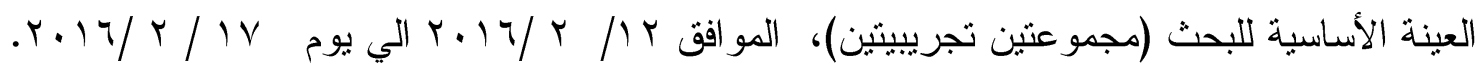

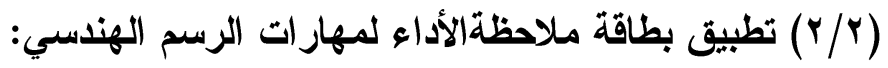

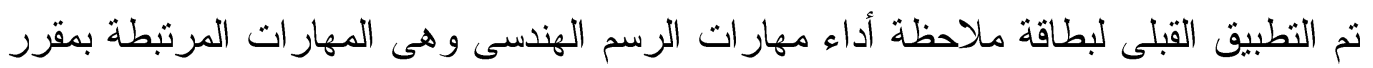

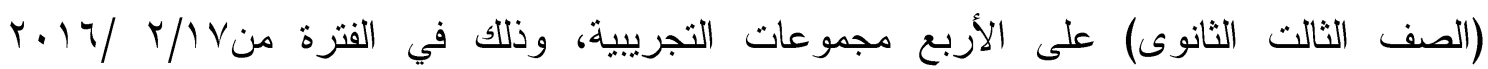

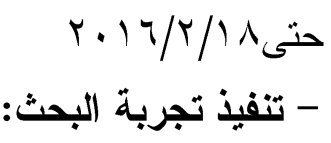

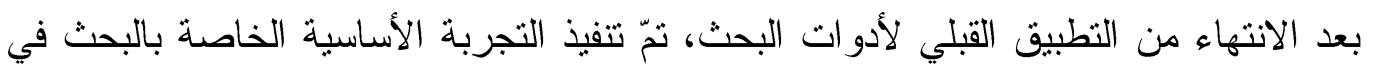

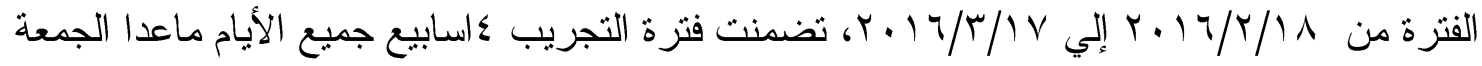
و العطلات الرسمية، حيث كان التعلم مستمر ا من مكان تو اجد المتعلم دون اشتر اط التو اجد بالمدرسة، وقد تم تتفيذ التجربة وفق الإجر اءات التالية. (1) إلمداد للتجربة:

- تمّ الحصول علي مو افقة السادة المشرفين علي تطبيق تجربة البحث. - قام الباحث بتحديد الخطة الزمنبة اللازمة لدراسة البيئة وتاريخ الانتهاء من تسليم المهام و الأنشطة الخاصة بالبيئة.

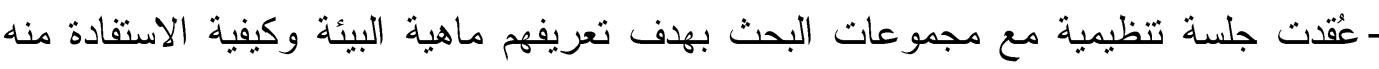
على النحو الأكمل، بالإضافة إلي كيفية السير داخل البيئة، وفى نهاية الجلسة نم تقسيم الطلاب إلي مجمو عتين تجريبيتين، وتحديد مو اعيد الدر اسة فى كل مجموعة من المجمو عثني.

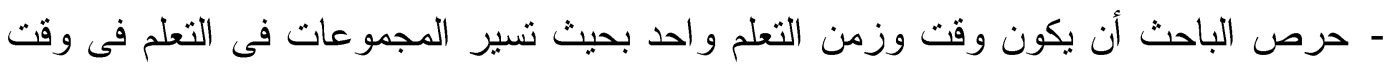
و واحد لتحقيق الضبط التجريبى. (r) ( التمهيد للتجريب: (r) وقد تمّ التمهيد لعملية التجريب وفقاً للإجر اءات الثالية. - لقاء تمهيدي لمعلمي عينة البحث؛ حيث يعرف فيه الباحث المتعلمين بصورة موجزة مفهوم البيئة

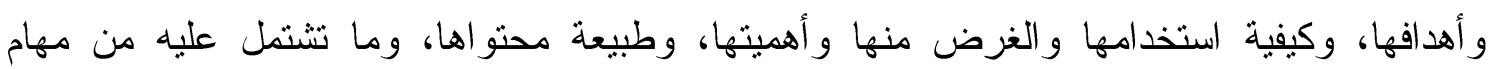


و أنشطة، وكيفية إنجازها، وتوجيه المتعلمين نحو طريقة الاستفادة القصوي من الموديلات التعليمية المتضمنة بالبيئة، و التعاون فيما بينهم و المشاركة في تبادل وحدات التعلم وقد تمّ في هذا اللقاء إثارة

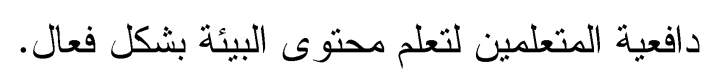

(r) الإعلام بموعد بلاية التجريب:

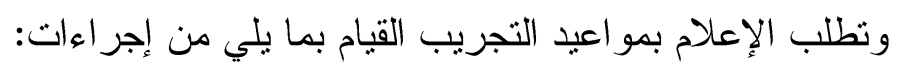

-إعلام جميع الطلاب عينة البحث من خلال اللقاءات مسبقاً بمو عد بداية التجربة الأساسية.

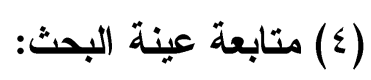

تمت عملية متابعة عينة البحث وفق ما يلهى

- ـ دخول جميع المتعلمين للبيئة من اليوم الأول لبداية تجربة البحث، ونمّ مثنابعة دخول المتعلمين للبيئة من خلال قاعدة البيانات للتعرف على مواعيد دخول وخروج المتعلمين و أدائهم

$$
\text { للاختبار ات، ومدى التقدم في در اسة مهار ات الرسم الهندسي. }
$$

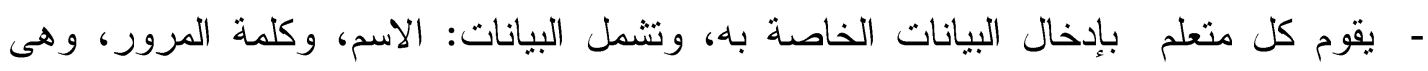

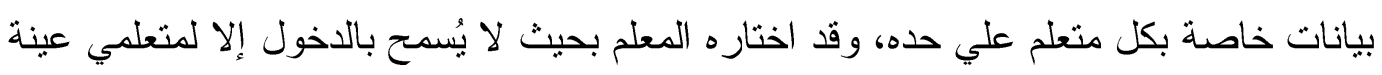

البحث فقط.

- لا يسمح للمتعلمين بالدخول لدر اسة محتوي البيئة ق قبل اجتياز الاختبار القبلي، والاختبار مصمم بحيث إذا حصل المتعلم علي أقل من (10 \% \%) فإنه بنتقل لدر اسة محتوي البيئة، أما إذا حصل المتعلم علي أعلي من (10 \% ) فتظهر له رسالة تبلغه بأنه ليس في حاجة لدراسة محتوي البيئة.

- ـ محتوي البيئة مقسم إلي أربع موديلات تعليمية أساسية وكل موديول يشنمل علي عدد من

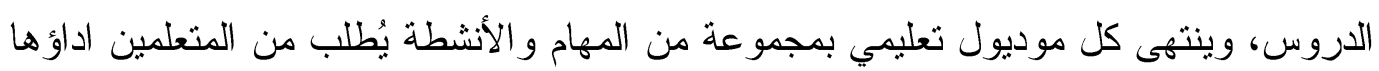
وفق الجدول الزمنى المحدد لتسليم المهام و الأنشطة. - ـيتم دراسة محتوي البيئة عن طريق الدخول إلي الموديلات التعليمية مباشرة من موقع البيئة وهو http://moustafa.elarn.net/"، ويختار المتعلم الموديول الذي بريد دراسته مباشرةً

$$
\begin{aligned}
& \text { على الإنترنت. } \\
& \text { (0) تطبيق أدوات القياس بعدياً: }
\end{aligned}
$$

بعد الانتهاء من تجربة البحث، تم تطبيق أدوات بالبحث ( الاختبار التحصيلي المعرفى، بطاقة

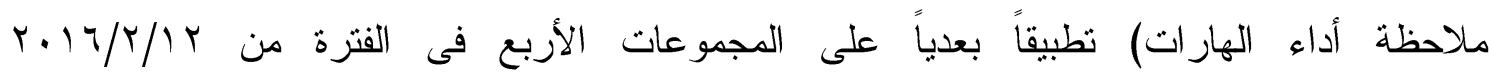

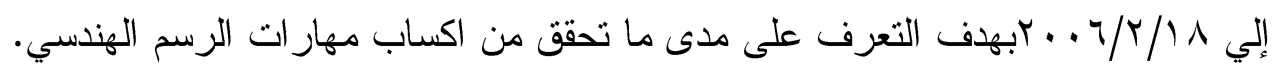
وقد تمّ التطبيق البعدي لأدو ات البحث بالطريقة نفسها التي طبق بها في التطبيق القبلي بحضور جميع المتعلمين، وذلك تمهيداً لتسجيل هذه النتائج ومعالجتها بالأساليب الإحصائية المناسبة. 
ثامناً: الأساليب الإحصائية المستخدمة في معالجة البيانات:

لاختبار فروض البحث، استخدمت الأساليب الإحصائية التالية:

T test -

لحساب دلالة الفرق بين متوسطي درجات المتعلمين - مجموعة البحث- في كل من التطبيقين القبلي و البعدي لكل من الاختبار التحصيلي وبطاقة الملاحظة.

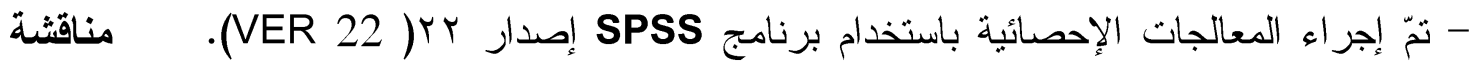

\section{نتائج البحث وتفسير اتها:}

يتضح من النتائج السابقة تفوق معلمين الرسم الهندسي في المجموعة الثانية و الذين درسوا من خلال

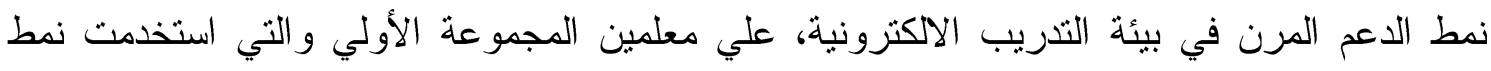

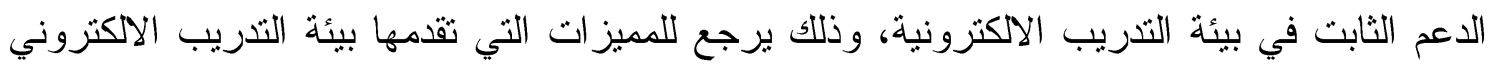

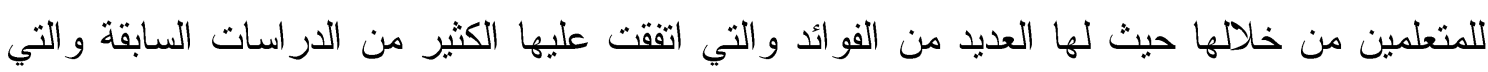

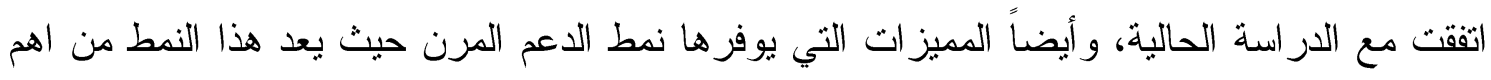
انماط الدعم المستخدمة بالنسبة للمتعلمين وذللك لانه يؤكد على تقديم التدعيم الفوري لكلا من الجانب المعرفي والجانب الأدائي المرتبط بالمهارات الخاصة بالرسم الهندسي، ومن ثم تتعكس على اهتمام

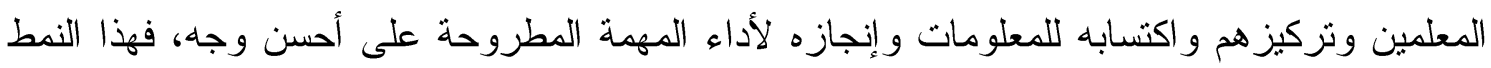

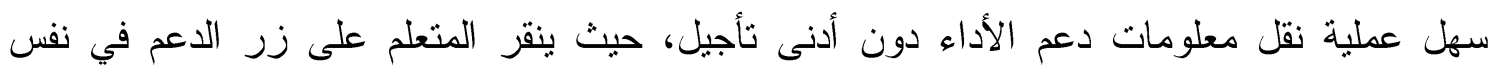

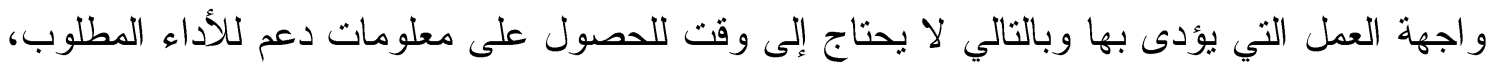

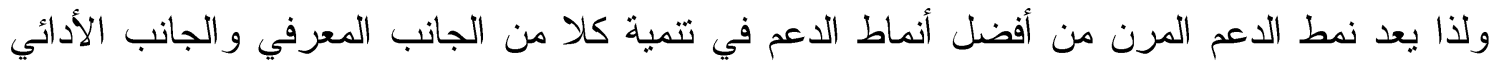

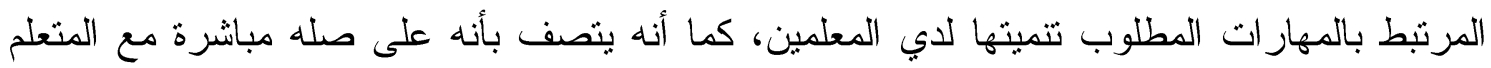

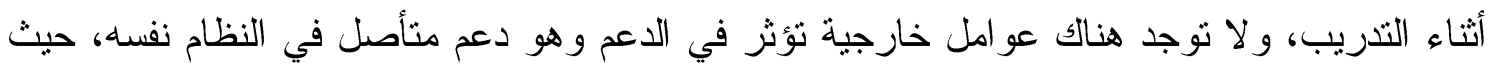

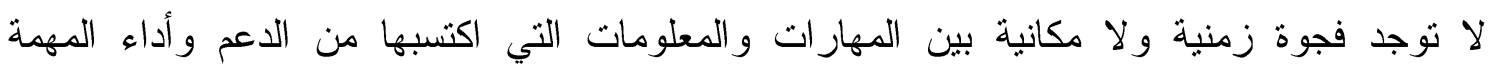

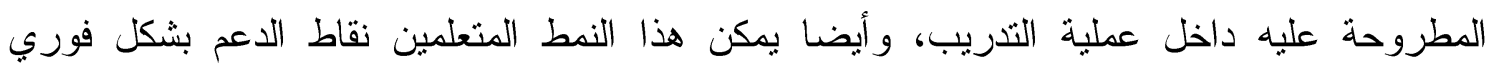

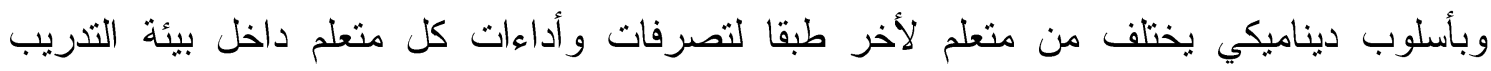
الاكترونية مما ساعد على تفوق المتعلمين الذنين استخدموه مقارنة بالمتعلمين الذين قامو الباستخدام نمط

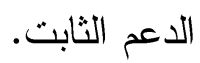




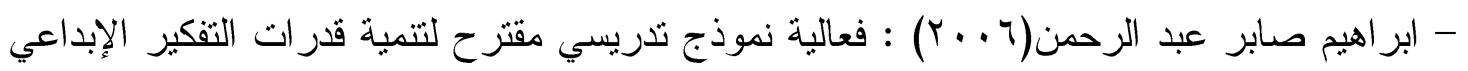

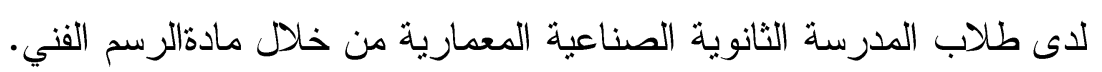
- اسامه خيرى محمد (r . . r) تتمية الاداء المهارى باستخدام الكمبيوتز وقياس فعاليته على تتمية

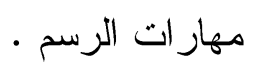

- أشرف عبد اللطيف الثنو انى (1 . . ب).المتطلبات التربوية لتعليم الحاسب الألى في المرحلة الثانوية العامة. رسالة ماجستير غير منشورة .كلية التزبية. جامعة حلوان. الاككتروني في التحصيل وكفاءة

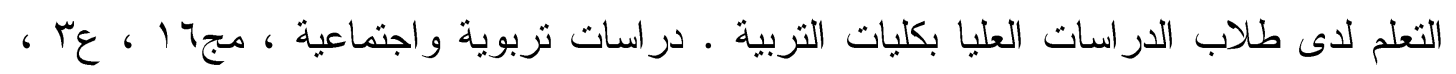
يوليو

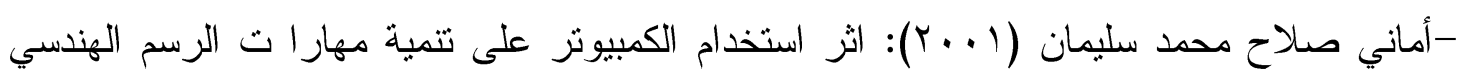
و الفني لطلاب التعليم الثانوي الصناعي ،رسالة ماجستير غير منشورة ،معهد الدراسات و البحوث التربوية جامعة القاهرة. - عبد الله بن عبد العزيز الموسي ؛ أحمد بن عبد العزيز المبارك: التعليم الإلكتروني : الأسس

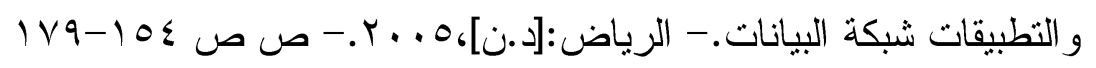
- زينب حسن حامد السلامي ، محمد عطية خميس (9 . . r). معايير تصميم وتطوير بر امج الكمبيوثز متعددة الوسائط.

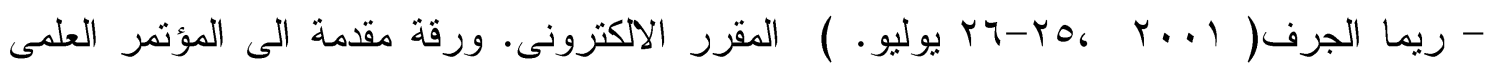
الثالث عشر للجمعية المصرية للمناهج وطرق الثدريس. ح" مناهج التعليم والثروة المعرفية و التكنولوجية المعاصرة . جامعة عين شمس .القاهرة - عبدالعزيز طلبة عبدالحميد (11 ـ ب). أثز التفاعل بين أنماط الدعم الاككتروني المتزامن وغير المنز امن في بيئة التعلم القائم على الويب و أساليب التعلم على التحصيل وتتمية مهار ات تصميم و انتاج مصادر التعلم لدى طلاب كلية التربية ـ دراسات في المناهج وطرق التثريس ، مصر ، ع .171

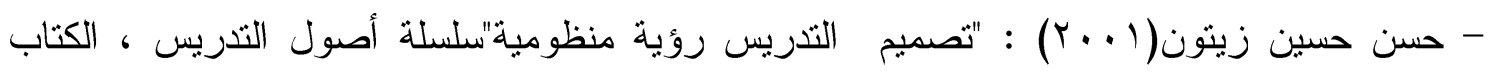
الثانى ،عالم الكتب ،المجلد (1).

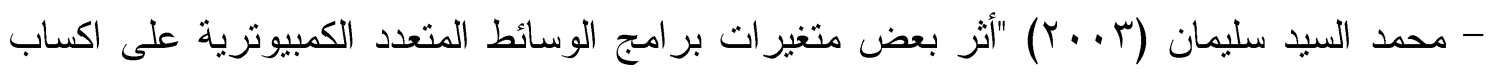
بعض مهار ات الرسم بالكمبيوثز لدى طلاب تكنولوجيا التعليم و اتجاهاتهم نحو استخدام الكمبيوتز

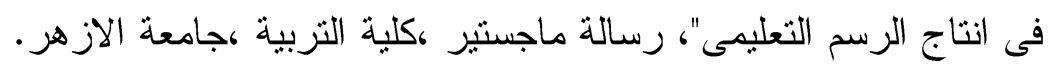


- ياسر شعبان عبد العزيز محمد: فاعلية التعلم التعاوني و الفردي القائم على الثبكات في تتمية مهارات استخدام البرامج الجاهزة لاى طلاب كليات الثربية واتجاهاتهم نحو التعلم الإلكتروني(رسالة

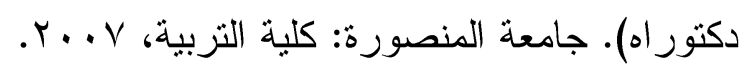

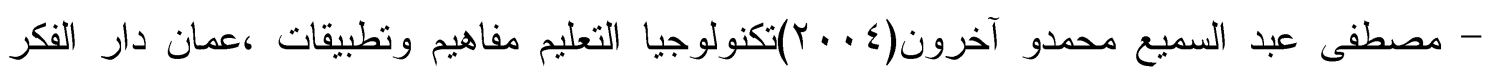
للنشر و التوزيع. مان.

- نبيل على (1 . . r) الثقافة العربية وعصر المعلومات ،سلسلة عالم المعرفة ، ب0 ، الكويت : المجلس الوطني للانقافة و الفنون و الآداب. لابل

- زينب حسن حامد السلامي (1 . . ب) أثز التفاعل بين نمطين من سقالات التعلم و أسلوب التعلم عند

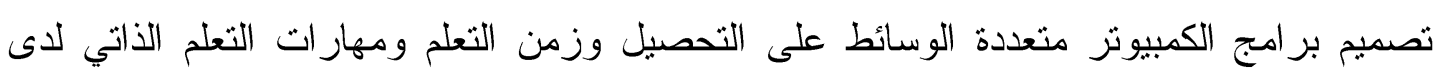
الطالبات المعلمات. رسالة دكتور اه غير منشورة ، كلية البنات ، جامعة عين شمس.

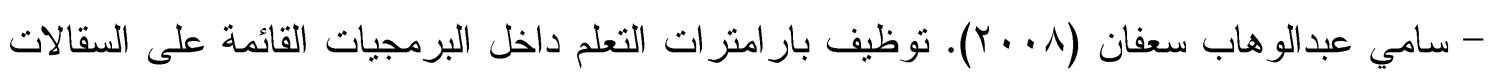
و أثنار ها على التحصيل المعرفي و المهارى لطلاب كلية المجنمع جامعة القصيم . مجلة الجمعية العربية لتكنولوجيا التربية ، ديسمبر .

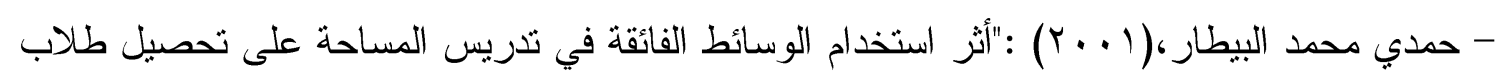

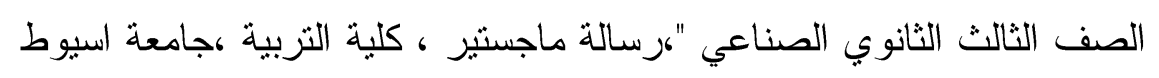
- سلطان هويدي سلطان المطيري (1 . . ب).أثر مدخل تكنولوجي متكامل في التدريب الإكتروني لتنمية بعض مهار ات إدارة المقررات الإلكترونية لدى أعضاء هيئة التدريس بكليات المعلمين بالمملكة

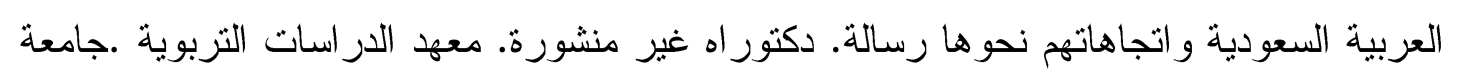
القاهرة. -فؤاد أبو حطب، وأمال صادق(1991). مناهج البحث وطرق التحليل الإحصائي في العلوم النفسية و التزبوية و الاجتماعية. القاهرة: مكتبة الأنجلو المصرية. - - صديق عفيفي (r . . r) التعليم عن بعد وحل مشكلات التعليم في مصر" المؤتمر القومي السنوي التاسع لمركز تطوير التعليم الجامعي ،التعليم الجامعي العربي عن بعد: رؤية مستقبلية ، جامعة

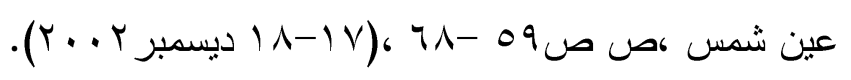




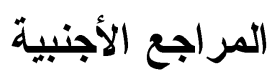

- Dabbagh, N. , Kitsantasm, A. (2005). Using Web-based Pedagogical Tolls as Scaffolds for self-regulated leaning. Instructional Science, 33.

- Fisher,F. , Schworm,D. ,Wallace,R. (2003). Help Seeking and Help. Design in Interactive Learning Environments . Review of Educational Research , 73 (3)

- Gustavo Prestera, E.(2003).Effects of Contextual Color on Recall: Bordrer Color as Alesson and Posttest Cue for Factual and Conceptual

- Huang,H. , et al. (2012). The Effectiveness of Using Procedural Scaffoldings in a Paper-Plus-Smartphone Collaborative Learning Context, Computer\&Education , 59.

- Lajoie, S. P. (2005). Extending the Scaffolding Metaphor. Instructional Science, 33(5 .(Merrill, D.M. (2005). The Executive Steps of the Training Using Computer

Networks. Technology in Society. V (16). Issue 2. Oct.

- Murdock Arnold keith Computer-Aided Drafting; perceived Needs of Virginia $\mathrm{s}$ Community College Drafting Instructor $\mathrm{s}$ ,D.A.I.vol.L.57,No.7,January1997

- McLoughlin, C. , Hollingworth, R. (2001). The weakest link: Is webbased learning capable of supporting problem-solving and metacognition? In ASCILITE 2001 Proceedings. - Nguyen, F. \& Klein, J. D. (2008). The Effect of Performance Support and Training as Performance Interventions. Performance Improvement Quarterly. 21(1). 95 - 114.

- Quintana,C. , Krajcik,J. , Soloway,E. (2002). Scaffolding Design Guidelines for Learner Centered Software Environments . Paper Presented at the Annual Meeting of the American Educational Research Association, New Orlean,LA,April 1-5,2002 .

- Raybould, B. (2000). Building Performance - Centered Web - based Systems, Information Systems، and Knowledge Management Systems in the 21st Century. Perform. Improve. 39(6). 69-79 .Jancarik, A. \& Jancarikova, K. (2010). Wiki Tools in the Preparation and Support of E-Learning Courses. Electronic Journal of e-Learning. 8(2). 123-132.

- Wolf,S.E. (2002). The Big Six Information Skill as a Metacognitive Scaffold in Solving Information Based Problems . The Degree Doctor of Philosophy, Arizona State University, Temp Arizona 